This paper was published as follows:

Camilleri, S.J., and C.J. Green, 2009, The impact of the suspension of opening and closing call auctions: Evidence from the National Stock Exchange of India, International Journal of Banking, Accounting and Finance, 1(3), 257-284.

Publication may be accessed at:

http://dx.doi.org/10.1504/IJBAAF.2009.022716

\title{
The Impact of the Suspension of Opening and Closing Call Auctions: Evidence from the National Stock Exchange of India
}

by

\section{Silvio John Camilleri and Christopher J. Green}

Camilleri: Banking and Finance Department, University of Malta

Green: Department of Economics, Loughborough University 


\begin{abstract}
We study the impact of the suspension of opening and closing call auctions by the National Stock Exchange of India in 1999. We compare volatility, efficiency and liquidity (VEL) of securities before and after suspension, and estimate the value of the auctions using an event study. Following suspension, VEL improved and the CARs were significant but not uniformly positive or negative. Also, less liquid stocks traded less in the auctions than other securities, especially at the opening, and they experienced gains following suspension. This is consistent with there being liquidity externalities associated with auctions, as appears to be the case in some industrial countries. We conclude that opening and closing call auctions may not necessarily improve share trading in a less liquid emerging market.
\end{abstract}

JEL Classification: G12; G14; G18

Keywords: Call Auctions, efficiency, event study, liquidity, stock markets, National Stock Exchange of India, volatility. 
This article is (C) Inderscience Publishers and is being made available on www.um.edu.mt on condition that it cannot be further copied/distributed or hosted elsewhere without the express permission from the copyright holders.

Camilleri, S.J., and C.J. Green, 2009, The impact of the suspension of opening and closing call auctions: Evidence from the National Stock Exchange of India, International Journal of Banking, Accounting and Finance, 1(3), 257-284.

\section{Introduction}

Two of the most important topics in market microstructure are the design of trading protocols and the evaluation of their effectiveness. Since trading protocols provide the framework within which markets operate they play a central role in price formation and discovery (Madhavan, 2000). Evaluating the effectiveness of different protocols is therefore a key concern for market authorities and regulators. One of the most hotly debated issues in this area is the effectiveness of call auctions as compared to continuous trading systems or to hybrid protocols featuring both systems. In theory, call auctions provide an efficient mechanism for aggregating diverse information because trading does not take place until price discovery has occurred (Economides and Schwartz, 1995), whereas under continuous trading, price discovery and trading take place simultaneously implying that trades may occur at "false" prices (Schwartz, 2000). However, continuous trading involves greater immediacy and therefore less price risk than an auction. Since there is a delay in establishing the trading price during an auction, the "true" price may change between the submission and execution of an order (Madhavan, 1992). Therefore, Economides and Schwartz (1995) argue for a hybrid system: an opening call auction to aggregate overnight information efficiently, followed by continuous trading during the day. Some of the major industrial stock exchanges have introduced an auction to open and in some cases also to close the day's trading (Ellul, Shin and Tonks, 2004).

Thus far, the empirical evidence on the effectiveness of auctions is inconclusive, with some studies identifying gains from the auction process but others finding that continuous trading is superior. We review this research in section 2. There are several possible reasons for this mixed evidence. First, call auctions vary in structure and different call auction structures may have different effects ${ }^{1}$. Second, different markets have different trading protocols, including listing requirements, price limits, and minimum tick sizes, and similarly-structured auctions may have different effects in a different market context (Kairys, Kruza and Kumpins, 2000b). Third, comparisons between call auctions and continuous trading will be difficult because the two systems being compared rarely share a common set of trading protocols (Madhavan, 2000). For example, much of the evidence on the effectiveness of 
This article is (c) Inderscience Publishers and is being made available on www.um.edu.mt on condition that it cannot be further copied/distributed or hosted elsewhere without the express permission from the copyright holders.

Camilleri, S.J., and C.J. Green, 2009, The impact of the suspension of opening and closing call auctions: Evidence from the National Stock Exchange of India, International Journal of Banking, Accounting and Finance, 1(3), 257-284.

call auctions is gleaned from markets where auctions are used to begin or end trading, but Amihud, Mendelson and Murgia (1990) show that, in Milan, there was little to choose in terms of efficiency as between continuous trading and call auctions which were not held at the beginning of the day. Other studies look at the impact of the replacement of call auctions by continuous trading (Amihud, Mendelson and Lauterbach, 1997), but such changes typically involve other reforms to the trading system making it difficult to conclude if costs or benefits are due to the switch to continuous trading or to other factors.

A further important limitation of the existing empirical literature on call auctions is that it is mostly concerned with the stock markets of the major industrial countries. Exceptionally, Shastri, Shastri and Sirodom (1995) investigated the impact of the opening call auction on the Bangkok stock exchange, and found that prices at the opening call were more volatile than during the rest of the day. This could be because uncertainty and therefore volatility are at their maximum early in the day following the overnight closing rather than because of deficiencies in the call auction system per se, and this is supported by the results of Amihud et. al. (1990). In general though, there has been very little research on stock exchanges in emerging markets. This is an important omission because most emerging stock markets are less liquid than the major industrial countries, and it has been argued that call auctions are particularly suited for trading less liquid stocks (Madhavan, 1992). This suggests that in emerging markets call auctions may have advantages over continuous trading systems in fostering the efficient trading of relatively illiquid securities. However, this argument also underlines a further difficulty in comparing call auctions and continuous trading: if the effectiveness of an auction depends on the liquidity of the market, a proper comparison must control for differences in stock liquidity, and possibly other factors.

In this paper we adopt a novel approach to the call-auction/continuous-trading debate. We investigate the impact of the suspension of opening and closing call auctions by the National Stock Exchange of India (NSE) on the 9th June $1999^{2}$. As far as we are aware, this is the first study of the impact of a suspension of a trading protocol. The NSE utilised an opening and closing call auction for some time 
This article is (C) Inderscience Publishers and is being made available on www.um.edu.mt on condition that it cannot be further copied/distributed or hosted elsewhere without the express permission from the copyright holders.

Camilleri, S.J., and C.J. Green, 2009, The impact of the suspension of opening and closing call auctions: Evidence from the National Stock Exchange of India, International Journal of Banking, Accounting and Finance, 1(3), 257-284.

before the suspension, and an important aspect of the suspension is that other market protocols and arrangements remained unchanged. Furthermore, since the continuous trading session took place both before and after the suspension, it is unlikely that the auctions would have limited the degree of immediacy in the market ${ }^{3}$. We are therefore studying two systems with otherwise identical trading protocols; and this makes for a relatively clean comparison. The NSE is an emerging market and includes a significant proportion of less liquid securities. This enables us to investigate differences in the effect of the auction suspension as between more and less liquid securities in the market ${ }^{4}$. Finally, there is growing practitioner interest in Indian markets and so far, relatively little research on India.

Our paper has two main objectives. First, we estimate the impact of the suspension of call auctions at the NSE, using the standard procedure of comparing the volatility, efficiency and liquidity (VEL) of traded securities in the market before and after suspension (Amihud, et. al., 1997). Second, we estimate the value of the call auctions to traders using an event study to calculate the cumulative abnormal returns (CARs) for the sample securities. If the auctions improved the price discovery process, we would expect to observe a deterioration in VEL following suspension: increased volatility, a reduction in open and close price efficiency and lower liquidity. The suspension of the auctions would be value-decreasing, and we would expect to find negative CARs. This would be in line with the findings of Pagano and Schwartz (2003) that the introduction of a closing call auction at the Paris Bourse created improvements in the price discovery process. If on the other hand, the auctions led to reduced immediacy and increased price risk then we would expect to observe an improvement in VEL following suspension, together with increased value and positive CARs. Ellul, Shin and Tonks (2004) argue that the value of call auctions may be limited by "thick market externalities" by which traders only enter the auction if they believe a sufficient number of other traders will be present so as to establish informationally-efficient prices.

Our tests suggest that average VEL broadly improved after the suspension of the auctions, but the mean CARs were generally negative. Therefore, we conducted further tests to examine the relationships between the responses to the auction suspension and the characteristics of the sample 
This article is (C) Inderscience Publishers and is being made available on www.um.edu.mt on condition that it cannot be further copied/distributed or hosted elsewhere without the express permission from the copyright holders.

Camilleri, S.J., and C.J. Green, 2009, The impact of the suspension of opening and closing call auctions: Evidence from the National Stock Exchange of India, International Journal of Banking, Accounting and Finance, 1(3), 257-284.

securities. It turns out that stock liquidity is an important factor in explaining the results which we obtain: less liquid stocks gained less from the auction than did more liquid stocks. This finding is consistent with the arguments of Ellul, Shin and Tonks (2004), and suggests that it cannot be assumed that call auctions will necessarily be of particular benefit in a less liquid emerging market.

The rest of the paper is structured as follows. In section 2 we review relevant theoretical and empirical literature on call auctions and continuous trading. Section 3 sets out some background material on the NSE and describes the data used in this study. In section 4, we investigate the impact of the suspension of call auctions on VEL. The event study is discussed in section 5 and the relationships among the estimated CARs and changes in VEL are explored. A concluding discussion and evaluation is given in section 6 .

\section{Research Background}

The central issue in the debate between call auctions and continuous trading is the trade-off between information efficiency and immediacy. Periodic call auctions aggregate information more efficiently, but they lack continuity and therefore reduce the immediacy of trading. However, these arguments are less relevant where call auctions are used at the opening or closing, since trading occurs continuously for the rest of the day. Moreover, lack of immediacy is an issue in any setting in which trades are clustered in a short period, and this may occur independently of an auction (Admati and Pfeliderer, 1988).

These considerations suggest that an opening call auction could improve pricing efficiency with little loss of immediacy as compared with continuous trading. Biais, Hillion and Spatt (1999) identified a clear price discovery process in the opening call auction of the (former) Paris Bourse: orders posted later in the call contained increasing amounts of information about the true price, while those posted early could be classified as noise. Davies (2003) found that most of the orders in the pre-opening period of the Toronto Stock Exchange were submitted with the intention of trading 5 . Amihud and Mendelson (1987) compared the opening call auction with the continuous trading session on the 
This article is (c) Inderscience Publishers and is being made available on www.um.edu.mt on condition that it cannot be further copied/distributed or hosted elsewhere without the express permission from the copyright holders.

Camilleri, S.J., and C.J. Green, 2009, The impact of the suspension of opening and closing call auctions: Evidence from the National Stock Exchange of India, International Journal of Banking, Accounting and Finance, 1(3), 257-284.

NYSE, and found that opening returns exhibited greater dispersion, higher negative autocorrelation and a larger residual error component than closing returns. Shastri, Shastri and Sirodom (1995) found that opening prices on the Thailand Stock Exchange, which are set by a call auction, tended to be more volatile than those of the rest of the day. However, since uncertainty is typically at its peak at the opening of a session, these results may just reflect the initial uncertainty, and not some inefficiency in the auction process itself. This point is supported by the results of Amihud, et. al. (1990) and Amihud and Mendelson (1991), who analysed call auctions which were not held at the start of the trading day and found that the auctions were no less efficient than continuous trading.

A more subtle argument is that participants in an auction may use the setup to conceal information from other traders. In the model of Caillaud and Mezzetti (2004) some participants give up profitable trading opportunities in an initial auction, in the hope that the resulting price movements generate higher subsequent profits. The experimental finding of Biais and Pouget (2000) suggest that there should be a pre-opening period prior to the auction, where a volume maximising price is announced on the basis of the incoming orders, but no trades are executed. This information augments price discovery in the opening call auction and continuous trading that follow.

Comerton-Forde and Rydge (2006) considered two empirical cases of manipulative orders: the first one for a liquid stock and the second one for an illiquid stock. They studied how auctions featuring different matching algorithms perform in dealing with market manipulation. The authors showed that manipulative orders can impact on the prices established in the auction and manipulation is less costly in illiquid stocks. In the case of the illiquid stock, a price was established in the presence of a manipulative order - yet the auction did not establish a price in the absence of the manipulative order. This casts doubts on the notion that auctions are particularly suited to trade less liquid stocks. This idea corroborates with the empirical findings of Madhavan and Panchapagesan (2000) who analysed the opening auction on NYSE. The authors found that call auctions might not be the ideal trading setup for less liquid stocks, given that the latter are considerably sensitive to order imbalances which might result in mispricings. 
This article is (C) Inderscience Publishers and is being made available on www.um.edu.mt on condition that it cannot be further copied/distributed or hosted elsewhere without the express permission from the copyright holders.

Camilleri, S.J., and C.J. Green, 2009, The impact of the suspension of opening and closing call auctions: Evidence from the National Stock Exchange of India, International Journal of Banking, Accounting and Finance, 1(3), 257-284.

The efficiency of call auctions also depends on the trading structure with which they are compared. Angel and $\mathrm{Wu}(2001)$ suggest that a dealer market may be better equipped than call auctions to handle the random nature of order imbalances, although they themselves advocate a hybrid trading mechanism incorporating features of call auctions and dealer markets. Call auctions should increase liquidity and reduce trading costs by batching small transactions which might have otherwise been executed sequentially (Economides and Schwartz, 1995). Ellul, Shin and Tonks (2004) found that small orders were cheaper to execute in the London Stock Exchange (LSE) call auctions, but larger orders were cheaper to execute in the contemporaneous off-exchange dealer market. Similarly, Kehr, Krahnen and Theissen (2001) found that Frankfurt Stock Exchange auctions provided transaction cost savings over continuous trading for small transactions, but not for large transactions.

The issue of whether call auctions constitute a better trading method for less liquid stocks has also been debated. Less liquid stocks may be subject to a greater degree of asymmetric information (Barry and Brown, 1984), implying that call auctions are especially suitable for trading such stocks. Comerton-Forde (1999) compared trading on the Australian Stock Exchange which commences with a call auction, with that on the Jakarta Exchange which commences with continuous trading. She concluded that the auction increased liquidity and reduced volatility in initial trading, particularly for less liquid stocks. However, Ellul, Shin and Tonks (2004) found that on the LSE, where trading at the opening and the closing may take place either through call auctions or the dealer system, less liquid stocks tended to trade more frequently in the dealer market, even if the call auctions offered cost savings and greater pricing efficiency. A possible explanation for this is that dealers guarantee the availability of a counterparty whereas call auctions depend to a higher degree on co-existing public orders. This creates a "thick market externality": traders will only enter an auction if they believe sufficient traders will be present so as to establish an informationally-efficient price. This may be an important issue in less liquid emerging markets.

Studies of changes in trading systems generally find that a switch from call auction to continuous trading increases stock values, for example in Paris (Muscarella and Piwowar, 2001), Tel Aviv 
This article is (C) Inderscience Publishers and is being made available on www.um.edu.mt on condition that it cannot be further copied/distributed or hosted elsewhere without the express permission from the copyright holders.

Camilleri, S.J., and C.J. Green, 2009, The impact of the suspension of opening and closing call auctions: Evidence from the National Stock Exchange of India, International Journal of Banking, Accounting and Finance, 1(3), 257-284.

(Amihud, et. al.,1997) and Warsaw (Henke and Lauterbach, 2005). However, Kalay, Wei and Wohl (2002) argued that these results may simply reflect investors' preferences for stocks that trade continuously rather than stocks that trade at auction, although causation could also be two-way. The changes in VEL of stocks in a switch from call auctions to continuous trading might also depend on the liquidity of different stocks. Kairys, Kruza, and Kumpins (2000a) found that when the Riga Stock Exchange shifted from a call auction to a continuous trading system, overall liquidity increased, but the benefits accrued to stocks which were already liquid while the volumes of smaller company stocks declined.

Ronen (1998) studied the impact of trading mechanisms on volatility by considering a change in the trading procedures on the Tel-Aviv Stock Exchange. The exchange used a call auction to end the trading day; yet in 1988 the mechanisms were reversed whereby the call auction was held prior to the continuous trading session. The author reported no significant differences in opening volatility following the change, concluding that the trading mechanism does not affect the opening volatility.

Aitken, Comerton-Forde and Frino (2002) analysed the introduction of a closing call auction on the Australian Stock Exchange, and noted that on high-volatility days, there is a pronounced tendency for traders to delay their trading till the auction. They suggested that call auctions are more highly valued by traders on high-volaitlity days. Despite this, one may question whether this effect might constitute a general tendency to postpone trading on high volatility days (in the hope that volatility reverts back to normal levels), irrespective of whether the session closes off with an auction or otherwise.

\section{Data and Notation}

Our study is concerned with the National Stock Exchange of India (NSE) which was established in 1994 and is one of two major Indian exchanges, along with the Bombay (Mumbai) Stock Exchange (BSE). In 2000, around 1,300 equities were traded on NSE, through 960 brokerage firms (Shah and Sivakumar, 2000). Most major stocks are quoted on both NSE and BSE which compete for listings 
This article is (C) Inderscience Publishers and is being made available on www.um.edu.mt on condition that it cannot be further copied/distributed or hosted elsewhere without the express permission from the copyright holders.

Camilleri, S.J., and C.J. Green, 2009, The impact of the suspension of opening and closing call auctions: Evidence from the National Stock Exchange of India, International Journal of Banking, Accounting and Finance, 1(3), 257-284.

and order flow. During the period covered by this paper there were around 400,000 transactions in a typical trading day on the NSE.

The NSE began with continuous, screen-based, nationwide electronic trading. Subsequently, the exchange introduced a pre-opening and post-closing call auction on an experimental basis. These followed the rule that the price should maximise the total quantity traded, implying that net demand or supply should be zero. Conditional orders such as "All-Or-None" were not considered in the auctions, but orders could be modified or cancelled during the sessions. Market buy (sell) orders were considered as orders which were prepared to trade at the highest (lowest) available price; they obtained the best price priority and were listed at the top of the order book in the auction sessions. For the rest of the trading day the system functioned as a continuous pure limit order book market, with time and price priorities applied to incoming orders. The opening and closing auctions were suspended without prior notice on June $9^{\text {th }} 1999$. The NSE did not subsequently reintroduce regular opening and closing auctions, although auctions may still be initiated by the exchange at any time for settlement-related reasons. When regular auctions were in effect, the opening auction was held between 09:30 and 09:45, followed by continuous trading until 15:30, and subsequently by a closing auction between 15:30 and 15:45. From June $9^{\text {th }} 1999$, continuous trading took place between 10:00 and 15:30. Our data period runs from March $2^{\text {nd }}$ through September $4^{\text {th }} 1999$, or for 63 days either side of June $9^{\text {th } 6}$.

The NSE offers particular advantages for a study of this kind. First, about 1,100 equities are traded enabling the selection of a large sample of stocks for analysis. Second, trading volumes are high for the most liquid stocks, but there is a wide range of trading volumes, and this enables an analysis of the relationships between liquidity and trading protocols. Third, there are no market-makers on the NSE, and therefore theories which suggest that market-makers are a factor in determining the relative efficiency of continuous trading versus call auctions will not affect the results of this study.

Table 1 about here 
This article is (C) Inderscience Publishers and is being made available on www.um.edu.mt on condition that it cannot be further copied/distributed or hosted elsewhere without the express permission from the copyright holders.

Camilleri, S.J., and C.J. Green, 2009, The impact of the suspension of opening and closing call auctions: Evidence from the National Stock Exchange of India, International Journal of Banking, Accounting and Finance, 1(3), 257-284.

Data were extracted from the NSE historical trades data $\mathrm{CDs}^{7}$. These include the volume and price of all trades on the exchange on a trade-by-trade basis. In selecting the sample securities, we considered only the more liquid equity issues in order to obtain sufficient observations for analysis. We selected 170 stocks with the highest quantities traded, and a further 170 stocks with the highest Indian Rupee value traded. We combined these samples, deleted 107 duplicated stocks and a further 51 stocks with missing observations or changes in equity structure (mergers, new share issues or stock splits), leaving a sample of 182 different stocks. The sample includes a wide range of liquidity: we only excluded stocks in which there was no trading at all in at least one day of the sample. We also utilised two different stock indices: the NSE Nifty, an index of the 50 most liquid stocks accounting for about $50 \%$ of NSE market capitalisation; and the BSE-500, an index of 500 shares quoted on the $\mathrm{BSE}^{8}$. For the comparison analyses and the event study, the sampling interval was homogenised by the use of daily data on volumes and prices (the last trade price for each stock, unless otherwise specified). Table 1 shows the data periods used for these analyses.

Subsequent to the suspension of the auctions it emerged that software problems may have caused the suspension'. Therefore, before conducting the main analyses, we checked to see if the auction system was inherently defective by examining auction outcomes for evidence of contamination. Clearly a contaminated auction would not provide a proper benchmark to evaluate auction performance vis-à-vis continuous trading. We looked first at the Nifty returns distributions during the opening and closing in the ten trading days before suspension and the ten trading days afterwards. If software problems were causing excessive price movements in the auction, we would expect to observe greater price dispersion during the auctions than without them. To achieve a clean comparison, allowing for the generally higher volatility at the opening and closing, we compared the opening (or closing) distributions in the auctions with the opening (or closing) distributions on continous trading days (table 2). It can be seen that the mean standard deviation (MSD) of the opening returns actually increased following suspension, indicating that it was unlikely that software problems in the opening 
This article is (C) Inderscience Publishers and is being made available on www.um.edu.mt on condition that it cannot be further copied/distributed or hosted elsewhere without the express permission from the copyright holders.

Camilleri, S.J., and C.J. Green, 2009, The impact of the suspension of opening and closing call auctions: Evidence from the National Stock Exchange of India, International Journal of Banking, Accounting and Finance, 1(3), 257-284.

auction had caused unjustified price movements for a sustained period prior to suspension. However, for the closing returns there is a significant decrease in the MSD suggesting the possibility of unjustified price movements in the closing auction.

We would expect suspension to occur immediately following the identification of mispricing. Therefore, we also compared the standard deviation of the opening (or closing) distribution on the last auction date (June $8^{\text {th }}$ ) with the MSD for the rest of the May $26^{\text {th }}$ to June $22^{\text {nd }}$ sample. The difference at the opening was again insignificant, suggesting that the June $8^{\text {th }}$ opening auction functioned normally, but the standard deviation at the closing was significantly higher on June $8^{\text {th }}$ than the MSD for the remaining days. Furthermore, if the June $8^{\text {th }}$ data is removed from the 10 day before-after comparison of the closings, the difference between the MSDs is no longer significant. This suggests that there may have been software problems but that these were confined to the June $8^{\text {th }}$ closing auction.

Tables 2, 3, 4 and Figure 1 about here

We checked this hypothesis directly by comparing the last closing auction (June $8^{\text {th }}$ ) with the closing calls of the preceding five trading days (table 3). The duration of the last auction was more than twice that of the other days, and the average interval between observations was twice as long. The change in the Nifty was much larger than in the other auctions, and the increase in the Nifty from 1162 to 1178 was reversed next day, when it closed back at 1162 . Figure 1 shows that price movements in the final closing auction were also far more volatile than those in the preceding five auctions. This tends to confirm our analysis that, if a software problem existed, its impact was confined to the last closing auction before suspension, and it did not affect the pricing process on other trading days. We conclude that, if a software problem occurred, it was in the June $8^{\text {th }}$ closing auction. This would explain the unexpected suspension on the following day. 
This article is (C) Inderscience Publishers and is being made available on www.um.edu.mt on condition that it cannot be further copied/distributed or hosted elsewhere without the express permission from the copyright holders.

Camilleri, S.J., and C.J. Green, 2009, The impact of the suspension of opening and closing call auctions: Evidence from the National Stock Exchange of India, International Journal of Banking, Accounting and Finance, 1(3), 257-284.

To get a more general idea of activity in the auctions before suspension, we selected three trading days at random from different days of the week and reasonably close to the suspension. Summary statistics of trading activity on these days for high, medium and less liquid stocks are shown in table 4. Trading frequencies increase with stock liquidity, and the level of activity is mostly higher for the closing auction than for the opening auction. A possible explanation for this is that unexecuted orders at the end of the continuous session were automatically carried forward to the closing call, whereas outstanding orders at the end of the day were not necessarily carried forward to the subsequent day's opening, since traders could cancel orders in anticipation of the overnight trading break.

\section{The Impact of Auction Suspension on Volatility, Efficiency and Liquidity}

\subsection{Volatility}

We assess the impact of suspension on market volatility by comparing the scaled intra-day price differences and overnight returns reversals, before and after the event. We also test if auctions helped to reduce volatility associated with "high-news" days using a GARCH model.

The scaled intra-day price difference (SIDP) is an indicator of intra-day volatility given by:

$$
D_{i, t}=\left(P_{\text {high }, i, t}-P_{\text {low,i,t }}\right) / P_{\text {open, }, i, t}
$$

where $P_{\text {high,i,t }}, P_{\text {low,i,t }}$ and $P_{\text {open,i,t }}$ are the highest, lowest and opening prices for security $i$ on day $t$ respectively. We see from table 5 that mean intra-day volatility decreased significantly in the postevent period, but there was no significant change in the standard deviations of $D_{i, t}$.

Overnight return reversals (ORR) are a measure of volatility between trading days. If the auctions help in price discovery, we would expect lower overnight volatility during the period when auctions were held, and vice-versa. A direct comparison between overnight returns in the pre-event and postevent periods is potentially misleading as higher price changes in one period might be justified by the news in that period. Thus we concentrate on the reversal of price movements. If price movements overnight and during the subsequent day are driven independently by the news in each respective 
This article is (C) Inderscience Publishers and is being made available on www.um.edu.mt on condition that it cannot be further copied/distributed or hosted elsewhere without the express permission from the copyright holders.

Camilleri, S.J., and C.J. Green, 2009, The impact of the suspension of opening and closing call auctions: Evidence from the National Stock Exchange of India, International Journal of Banking, Accounting and Finance, 1(3), 257-284.

period then we would expect there to be no systematic relation between overnight and next-day returns. If however, overnight price movements are systematically reversed next day, this implies that the overnight movement was excessive and gives evidence of excess volatility. To test for this we regress the daily return $\left(r_{i, t}\right)$ on the previous overnight return $\left(r_{i, t}^{O}\right)$ :

$$
r_{i, t}=\mu_{i}+\pi_{i} r^{o}{ }_{i, t}+\varepsilon_{i, t}
$$

A significant negative $\pi_{i}$ gives evidence of price reversals and therefore of excess volatility.

Table 5 about here

The cross-company mean of the slope coefficients $(\pi)$ is negative in both the pre-event and post-event period (table 5). Furthermore, there was a significant increase in $|\pi|$ following suspension of the auctions implying an increase in volatility, in contrast to the results for SIDP. We checked that there were no further events which might have impacted on volatility during this period by reviewing relevant NSE circulars. On June $16^{\text {th }}$ the National Securities Clearing Corporation applied additional volatility margins in respect of outstanding positions of trading members in highly volatile stocks. This might have discouraged members from increasing positions in volatile stocks and therefore might be expected to reduce volatility as between the pre-event and post-event period. Furthermore only four of the affected stocks are included in our sample, indicating that the additional volatility margins were unlikely to have affected our results.

A more general issue is that most Indian companies have their accounting year-end in March, and release their annual reports between March and June, in the pre-event window. It could be argued that one might expect higher volatility in the pre-event window just because of the clustering of earnings reports. However, Ball and Brown (1968) found that the impact of an earnings surprise on a company's share price typically begins several months before the release of the annual report, and is almost fully impounded into the price by the time of the earnings announcement. Furthermore, even 
when there is a surprise in the announcement, the impact of the news on share prices and spreads is generally dissipated during the day of the announcement itself in as little as 15-30 minutes (Patell and Wolfson, 1984; Kim and Verrecchia, 1994). This suggests that any effect of such announcements on pre-event window volatility would have been at most small, and confined to the SIDP measure ${ }^{10}$. To verify this argument we checked the robustness of our findings using the results of Camilleri and Green (2005). In that paper, we identified a monthly seasonal pattern of volatility in the NSE Nifty in which volatility does tend to be higher in March and April than in other months, perhaps due to the bunching of year-end reporting. We used the volatility estimates from Camilleri and Green (2005) to adjust the SIDP statistics for these systematic seasonal volatility differences, and we then re-performed the SIDP comparisons. The results (given in Appendix A) are very similar to those in table 5 and clearly show a very significant fall in SIDP following suspension.

Even if auctions were not associated with a general reduction in volatility, it is still possible that they may have been useful on "high-news" days when greater volatility may be expected. To investigate this we estimated EGARCH models of the Nifty ${ }^{11}$ before and after suspension. If auctions helped dampen volatility on "high-news" days we would expect to see an increase in the effects of news on the conditional variance, post suspension. In fact, the coefficients in the EGARCH model were mostly insignificant (table 5) and, if anything, there was a reduction in the effects of news post-suspension, both for "good news" shocks $(\alpha+\gamma)$ and for "bad news" shocks $(\alpha-\gamma)$. On balance therefore, it seems clear that the auctions did not materially reduce market volatility. 
This article is (C) Inderscience Publishers and is being made available on www.um.edu.mt on condition that it cannot be further copied/distributed or hosted elsewhere without the express permission from the copyright holders.

Camilleri, S.J., and C.J. Green, 2009, The impact of the suspension of opening and closing call auctions: Evidence from the National Stock Exchange of India, International Journal of Banking, Accounting and Finance, 1(3), 257-284.

\subsection{Pricing Efficiency}

Relative Return Dispersion (RRD) is our first test of pricing efficiency. Following Amihud et. al. (1997), $R R D_{t}$ across the sampled securities during time $t$ is defined as:

$$
R R D_{t}=\frac{1}{n} \sum_{i=1}^{n} \varepsilon^{2}{ }_{i t}
$$

In (3), $\varepsilon_{i t}$ are the residuals from the market model for security $i$ at time $t$, and $n$ is the number of sampled securities. A lower $R R D_{t}$ indicates a lower pricing error and therefore greater efficiency. The results in table 6 indicate that $R R D_{t}$ decreased very significantly suggesting that pricing became more efficient following suspension of the auctions.

The autocorrelation of returns is our second measure of pricing inefficiency. If prices adjust fully to new information, price changes should be uncorrelated provided that the flow of news is also uncorrelated, as we would expect. We calculated first-order autocorrelation coefficients for each stock and most of the individual coefficients and the means were not significantly different from zero, suggesting that the sample stocks were efficiently priced in both periods (table 6). There is a significant change in the autocorrelation coefficient as between the pre-event and post-event period, from predominantly negative to predominantly positive, suggesting that the nature of the price discovery process may have changed following suspension of the call auctions. For the measurement of efficiency however, the sign of the autocorrelation is immaterial; inefficiency is present if the autocorrelation is significantly different from zero, whether positive or negative. Given the change in sign from pre- to post-suspension, we checked the size of the autocorrelations by comparing the squared autocorrelation coefficients across firms. This confirms an improvement in market efficiency, although the improvement was not significant according to this second test.

Tables 6 and 7 about here 
This article is (C) Inderscience Publishers and is being made available on www.um.edu.mt on condition that it cannot be further copied/distributed or hosted elsewhere without the express permission from the copyright holders.

Camilleri, S.J., and C.J. Green, 2009, The impact of the suspension of opening and closing call auctions: Evidence from the National Stock Exchange of India, International Journal of Banking, Accounting and Finance, 1(3), 257-284.

Auctions are thought to have particular value at the opening when it is necessary to aggregate overnight information to set prices early in the day. Therefore, we also used higher frequency (intraday) data to investigate the price discovery process in the early part of the trading day before and after suspension. If the opening auctions were valuable in price discovery, prices should move more quickly to their fundamental values and exhibit less autocorrelation than in the absence of the auction. We investigated this by calculating successive one minute returns on the Nifty in the first hour of trading, for 25 trading days before and 25 days after suspension ${ }^{12}$. There was a significant decrease in the autocorrelation as between the pre- and post-suspension periods (table 6), suggesting that the auctions did not help in price discovery, even at the opening. Thus, pricing efficiency generally increased after auction suspension, both during the trading day and within the first hour of the day.

\subsection{Liquidity}

Two measures were selected to assess the impact of suspension on market liquidity: the number of shares traded and the volume per unit of return. The number of shares traded increased significantly following suspension (table 7) suggesting that market liquidity improved between the two regimes. Volume per unit of return (the ratio of volume to the absolute return) is an estimate of how much trading is associated with a unit price change. This measure assesses the resiliency aspect of liquidity: how much activity is required to generate a unit price change. The more resilient is the market, the greater is the activity required to change the share price in either direction. This statistic also indicates a significant increase in market liquidity following suspension of the auctions (table 7). Of course, we would expect share volumes to trend upwards, even perhaps in the relatively short window within which our analysis is conducted. To check this point we estimated a simple time trend regression for volume traded with shift and trend dummies at the suspension date. This covered a longer-run period: January 1995 through December 2003; and it provides confirming evidence that there was a significant step increase in volume, though a small decrease in trend, following suspension of the auctions (table 7). 
This article is (C) Inderscience Publishers and is being made available on www.um.edu.mt on condition that it cannot be further copied/distributed or hosted elsewhere without the express permission from the copyright holders.

Camilleri, S.J., and C.J. Green, 2009, The impact of the suspension of opening and closing call auctions: Evidence from the National Stock Exchange of India, International Journal of Banking, Accounting and Finance, 1(3), 257-284.

In summary, the evidence on VEL changes is not uniform, but a substantial majority of our tests suggests that there was an improvement in VEL following suspension of the auctions.

\section{The Value of Opening and Closing Auctions to Shareholders}

\subsection{Method}

We turn next to an event study to assess the value to shareholders of the suspension of the call auctions. Event study methods are explained in detail by MacKinley (1997), so we content ourselves with a brief summary. We used the market model adjusted for calendar time effects as our model of equilibrium returns:

$$
r_{i, t}^{\prime}=\alpha_{i, t}+\beta_{i} r_{m, t}^{\prime}+\varepsilon_{i, t}
$$

where: $r_{i, t}$ is the return of stock $i$ on day $t ; r_{m, t}$ is the market return; $r_{i, t}^{\prime}=r_{i, t} / k_{t} ; r_{m, t}^{\prime}=r_{m, t} / k_{t} ; k$ is the return interval in calendar days; $\alpha_{i}$ and $\beta_{i}$ are the estimated coefficients; and $\varepsilon_{i, t}$ is the error term. More elaborate equilibrium models do not usually yield significant gains in efficiency or unbiasedness in the measurement of the abnormal returns which are the key output of an event study (MacKinlay, 1997; Cable and Holland, 1999). All our stocks were traded every day in the sample period, and so no adjustments were necessary to allow for thin trading. Daily abnormal returns for each firm in the event window $\left(A R_{i, t}\right)$ were calculated as:

$$
A R_{i, t}=\left[r_{i, t}^{\prime}-\left(\hat{\alpha}_{i}+\hat{\beta}_{i} r_{m, t}^{\prime}\right)\right] k_{t}
$$

and then cumulated over time to obtain the cumulative abnormal returns (CARs):

$$
C A R_{t, i}=\sum_{t=T-2}^{T+15} A R_{t, i}
$$

Finally, we averaged the CARs across the $n$ sample firms to obtain:

$$
A C A R_{t}=\frac{1}{n} \sum_{i=1}^{n} C A R_{i, t}
$$


This article is (C) Inderscience Publishers and is being made available on www.um.edu.mt on condition that it cannot be further copied/distributed or hosted elsewhere without the express permission from the copyright holders.

Camilleri, S.J., and C.J. Green, 2009, The impact of the suspension of opening and closing call auctions: Evidence from the National Stock Exchange of India, International Journal of Banking, Accounting and Finance, 1(3), 257-284.

For this study, the event date $(t=T)$ is June $9^{\text {th }} 1999$, and the event window runs from $T-2$ to $T+15$, a total of 18 days. A short pre-event window is suggested by the fact that the suspension was not trailed in advance. The longer post-event window covers the possibility that the change might take time for markets to evaluate, in part because different market participants might interpret it differently. A yet longer event window is not desirable here, as it would reduce the power of the tests (MacKinlay 1997), and the CARs may be diluted by unrelated factors. Normally, the estimation window precedes the event window, but this may create post-selection bias if the event is conditional on the characteristics of the securities. (Amihud, et. al., 1997). In this case, the event was not conditional on stock characteristics, and we therefore used a pre-event estimation window, from $T-62$ to $T-3$.

We used as market index the BSE-500. We took the view that it was desirable to use a broad-based index and the key NSE Nifty index comprised just 50 stocks during the sample period. We believe that this choice of index is reasonable, given that major Indian stocks are quoted on both NSE and BSE, and both exchanges are subject to the same systematic risk ${ }^{13}$. Daily data create a range of problems in event studies (Brown and Warner, 1985). The main concern for this study is the typical non-normality of daily stock returns which creates problems for accurate inferences concerning the ARs, and suggests that we should not rely exclusively on standard t-tests. We pursue this issue in section 5.2 next.

\section{$5.2 \quad$ Results}

OLS estimates of the market model and relevant diagnostics show that, in general, the model performed very well (table 8). The betas are generally plausible; the F tests indicate that almost all the regressions have a good overall fit; and the diagnostics show that there is no serious evidence of misspecification or structural breaks. This is important for our research, given that a frequent criticism of event studies is that inferences may be flawed because of time-varying betas. The diagnostics indicate that betas were generally stable over our sample period. The results of the predictive failure test are particularly strong, given that the 18 out-of-sample observations used for the test were in the 
This article is (C) Inderscience Publishers and is being made available on www.um.edu.mt on condition that it cannot be further copied/distributed or hosted elsewhere without the express permission from the copyright holders.

Camilleri, S.J., and C.J. Green, 2009, The impact of the suspension of opening and closing call auctions: Evidence from the National Stock Exchange of India, International Journal of Banking, Accounting and Finance, 1(3), 257-284.

event window. It suggests that we can be reasonably confident that the model did not change following the event. The autocorrelation and heteroscedasticity tests do not reject the null hypothesis for most stocks.

Table 8 about here

The only diagnostic which seems problematic is the normality test where the null of normally distributed errors is rejected for $51 \%$ of stocks. In fact, there are just a few abnormally high JarqueBera statistics. For the 6 highest, the fitted model mimicked actual market movements reasonably well, except for a few positive outliers, possibly due to company announcements. Otherwise, the residuals were mostly close to zero, and almost uniformly distributed. This suggests that the estimated coefficients will be close to their true values, and the main objective in dealing with this non-normality should be to enhance the power of the significance tests of the ARs, rather than to obtain better estimates of the regression coefficients. For this, we follow MacKinnon (2002) who argued that bootstrap tests usually perform better in these circumstances than standard t-ratios. The advantage of bootstrapping in the present context is that it relies only on the assumption of random sampling from the data at hand, and does not require any distributional assumptions. Since we are interested in the significance of the ARs rather than their sign, we compare the error sum of squares in the estimation period to that in the event window for each stock. For a valid comparison, we rescale the latter by the ratio of the numbers of observations in the estimation window to that in the event window. Hence:

$$
\begin{aligned}
& \text { S.S.R. } E_{i, e s t}=\sum_{t=T-62}^{T-3} \varepsilon_{i, t}{ }^{2} \\
& \text { S.S.R.E } E_{i, \text { event }}=\frac{60}{18} \sum_{t=T-2}^{T+15}\left[\varepsilon_{i, t}\right]^{2}
\end{aligned}
$$

where: S.S.R.E $E_{i, e s t}$ and S.S.R.E $E_{i, e v e n t}$ are the Sums of Squared Rescaled Errors for stock $i$, in the estimation period and in the event window respectively. The mean S.S.R.E $E_{\text {est }}$ was 0.0787 whilst that 
This article is (C) Inderscience Publishers and is being made available on www.um.edu.mt on condition that it cannot be further copied/distributed or hosted elsewhere without the express permission from the copyright holders.

Camilleri, S.J., and C.J. Green, 2009, The impact of the suspension of opening and closing call auctions: Evidence from the National Stock Exchange of India, International Journal of Banking, Accounting and Finance, 1(3), 257-284.

for S.S.R.E $E_{\text {event }}$ was 0.2429 ; a difference of 0.16419 . To test the significance of this difference, we combined the S.S.R.E.s for all stocks in the estimation period and the event period, into a single sample of 364 S.S.R.E.s. Observations were then drawn randomly without replacement from this population, creating two equally-sized sub-samples. The difference between the means of these subsamples was recorded, and the drawing repeated 5,000 times ${ }^{14}$. The results are summarized in Figure 2 where we see that 0.16419 actually lies outside the bootstrapped distribution, implying that we can reject the null hypothesis of equal means at the $99.98 \%$ level $^{15}$ (at least) and conclude that the ARs are highly significant.

Figures 2, 3 about here

The cross-section average CARs for all stocks are shown in figure $3^{16}$. After an initial increase, the CARs decrease until about $\mathrm{T}+9$; and then drift up again ${ }^{17}$. The initial positive and later increasing CARs might correspond to the broad improvement in VEL, but the range of negative CARs is harder to reconcile with the calculated VEL changes. Therefore, we consider next the possible linkages between the CARs and VEL changes.

\subsection{CARs and Volatility, Efficiency and Liquidity}

The relationships between the CARs and changes in VEL are investigated by performing two sets of cross-section regressions. First, we check if the changes in VEL among stocks are related to their liquidity. Second, we seek to explain the cross-sectional variation in the CARs by changes in VEL factors and liquidity levels. We concentrate on liquidity because of the debate over the relationship between stock liquidity and the benefits of an auction. We began by regressing the changes in 4 of our VEL measures on two dummy variables measuring the pre-event liquidity of the sample stocks: low and high liquidity. Since our volatility measures gave different results as to the effect of the auction suspension, both SIDP and ORR were used as regressands. For efficiency and liquidity, the measures showed the same qualitative effect of the auction suspension, so only one of each measure was used: 
This article is (C) Inderscience Publishers and is being made available on www.um.edu.mt on condition that it cannot be further copied/distributed or hosted elsewhere without the express permission from the copyright holders.

Camilleri, S.J., and C.J. Green, 2009, The impact of the suspension of opening and closing call auctions: Evidence from the National Stock Exchange of India, International Journal of Banking, Accounting and Finance, 1(3), 257-284.

the change in Relative Return Dispersion and the change in the Volume-Return Ratio ${ }^{18}$. We see in table 9 that these regressions have little explanatory power and neither of the liquidity dummies is significant, suggesting that the observed VEL changes are unrelated to stock liquidity. 
We turn next to the regressions explaining the CARs. Although the CARs are statistically significant, there is an increasing and a decreasing segment. We therefore regressed the increasing CARs from $\mathrm{T}+9$ through $\mathrm{T}+15$ on changes in VEL which showed an improvement, and on the pre-event liquidity dummies. The decreasing CARs from $\mathrm{t}=\mathrm{T}$ through $\mathrm{T}+8$ were regressed on the overnight return reversal coefficient $(\pi)$ which indicated a worsening of volatility, as well as on pre-event liquidity. For the increasing CARs (Table 10, Panel A), Relative Return Dispersion and the Volume Return Ratio each have the expected sign although the former is not significant, whereas the Scaled Intra-Day Price Difference is significant but with an unexpected sign. The liquidity dummies are insignificant, confirming that initial liquidity does not help explain the positive CARs. These are contrary to the results of Kairys, Kruza, and Kumpins, (2000a) who found that in Riga increased liquidity largely accrued to the most liquid stocks.

For the decreasing CARs (Panel B), Overnight Return Reversals are positive as expected and marginally significant. The dummy for less liquid stocks is also significant and suggests that the least liquid stocks experienced higher CARs following abolition of the auctions. However, as the dummy for the most liquid stocks is also positive but insignificant, we cannot conclude that there is a welldefined relationship between liquidity and the CARs. To check these results we split the whole sample into high, medium and less liquid stocks and recalculated the mean CARs (Figure 4). This confirms that there is a difference between the CARs of the less liquid stocks (Sample A) and those of medium and high liquidity stocks, providing some support to the argument that call auctions may not be of benefit to less liquid stocks (Ellul, Shin and Tonks, 2004).

Figure 4 about here 
This article is (C) Inderscience Publishers and is being made available on www.um.edu.mt on condition that it cannot be further copied/distributed or hosted elsewhere without the express permission from the copyright holders.

Camilleri, S.J., and C.J. Green, 2009, The impact of the suspension of opening and closing call auctions: Evidence from the National Stock Exchange of India, International Journal of Banking, Accounting and Finance, 1(3), 257-284.

\section{Further Discussion and Conclusions}

\subsection{Some Possible Explanations}

Following auction suspension, we find that volatility, efficiency and liquidity on the NSE broadly improved, although one measure of volatility deteriorated. An improvement in price discovery is also apparent in the first hour of the day's trading. These improvements are not accompanied by unambiguously positive CARs after the suspension, as shown in figure 3. After an initial increase in the 2 days preceding suspension, the CARs are negative for most companies for most of the post-event window: first decreasing then increasing. We consider five possible explanations for this apparent inconsistency.

First, improvements in VEL may have been priced in before the suspension, even though it was announced on the day of implementation. This may imply insider trading, or that the suspension was expected by the market. However, changes which affect the structure of trading can be difficult to price in fully before the event because the volume and composition of trading after the event is not known for certain beforehand. Similarly, it is unlikely that the event was anticipated given that it appears that auctions were suspended immediately after evidence of pricing problems materialised.

Second, the cross-section regressions provide only limited support for the impact of VEL improvements on the CARs in that the increasing part of the CARs are explained to some extent by the positive changes in VEL factors, but not all with the expected sign. One possibility is that the downward sloping part of the CARs was an initial overreaction which was subsequently reversed. This is consistent with the finding that the overreaction was confined to the more liquid stocks, as our evidence suggests that these gained less from suspension than did the less liquid stocks.

Third, intra-day volatility decreased whilst overnight volatility increased. A possible explanation for this is that the opening auctions did not reduce intra-day volatility, but the closing auctions did help reducing overnight volatility. Existing literature does suggest some reasons why closing auctions may 
This article is (C) Inderscience Publishers and is being made available on www.um.edu.mt on condition that it cannot be further copied/distributed or hosted elsewhere without the express permission from the copyright holders.

Camilleri, S.J., and C.J. Green, 2009, The impact of the suspension of opening and closing call auctions: Evidence from the National Stock Exchange of India, International Journal of Banking, Accounting and Finance, 1(3), 257-284.

be more effective than opening auctions. Hillion and Suominen (2004) found that closing auctions may reduce the potential for market participants to manipulate closing prices. Conversely, Caillaud and Mezzetti (2004) suggest that, in an opening auction, participants might be able to conceal information from other traders. On the NSE, there was less activity at the opening call than the closing call, particularly for less liquid stocks. Thus, we may hypothesise that whilst closing auctions helped to establish more efficient prices and therefore reduce overnight volatility, this was not happening at the opening auctions because of insufficient activity, particularly for less liquid stocks.

Fourth, the results could be related directly to the different liquidity of the shares. The CARs for the less liquid stocks were unambiguously positive, whereas the high and medium liquidity stocks exhibited initially small positive CARs then larger negative CARs (figure 4). This is consistent with the view that higher liquidity stocks did benefit from the call auctions but low liquidity stocks did not. This too could be because the less liquid stocks traded much less actively in the call auctions and therefore had little to lose from suspension. However, this does not explain why VEL improved on average for all stocks following suspension and that there is no clear cross-sectional relationship between liquidity and the VEL factors.

Fifth and finally, it is possible that the call auctions had utility for specific types of investors, especially domestic or foreign institutions which may be key providers of market liquidity at certain times. Available data does not permit a direct test of this hypothesis, but it seems unlikely that call auctions would have benefits for domestic institutions which would not be picked up in our general tests. However, at the time of this analysis, foreign institutional investors (FIIs) were subject to firmspecific ceilings on the percentage share they were permitted to hold in individual Indian companies. Once this ceiling was approached, FIIs were required to dispose of part of their holdings and a liquid market would be essential for this to function smoothly. The call auctions may have facilitated this process and, soon after they were suspended, the NSE introduced (in December 1999) a new trading segment specifically to enable FIIs to dispose of security holdings in excess of the permitted maxima. 
This article is (C) Inderscience Publishers and is being made available on www.um.edu.mt on condition that it cannot be further copied/distributed or hosted elsewhere without the express permission from the copyright holders.

Camilleri, S.J., and C.J. Green, 2009, The impact of the suspension of opening and closing call auctions: Evidence from the National Stock Exchange of India, International Journal of Banking, Accounting and Finance, 1(3), 257-284.

Taken together, these explanations suggest that the call auctions were not as effective as might have been expected, particularly at the opening, and particularly for less liquid stocks. This is consistent with Schwartz (2000) who argued that it is essential that call auctions attract a critical mass of order flow, otherwise they may fail.

\subsection{Summary of Conclusions}

To our knowledge this is the first study to compare call auctions and continuous trading following a suspension, where no other changes in market protocols took place. It is also concerned with an emerging market where low liquidity is a more pervasive problem than in the major industrial countries. Our main conclusions from the study can be summarised as follows. First, we confirm the prevailing wisdom that market microstructure changes do have measurable and significant effects on stock prices and on market performance measures such as volatility, efficiency and liquidity. We found that VEL broadly improved following the auction suspension but the CARs, though significant, did not exhibit a uniformly positive or negative pattern. As a corollary, it is evident that call auctions do not necessarily create an improvement in VEL factors as suggested inter alia by Madhavan (1992), for we find the reverse to be true.

Second, we do not find a clear-cut market reaction to the suspension. The CARs are significant but initially they decrease and then subsequently increase. The cross-sectional relationships between the CARs and the underlying VEL factors are also imprecise. Stocks which experienced the most improvements in efficiency and liquidity also experienced higher CARs, although the efficiency effect was not significant. The improvement in intra-day volatility had a positive impact on the cross-section of CARs, while the deterioration in inter-day volatility had the expected negative effect.

Third, we conjecture that a source of these conflicting findings may lie in the liquidity of the sample securities. We find a difference in the response to the auction suspension as between less liquid and more liquid stocks. Less liquid stocks traded less in the auctions than other securities, especially at the opening, and they experienced the most gains following suspension. The results suggest that less 
This article is (C) Inderscience Publishers and is being made available on www.um.edu.mt on condition that it cannot be further copied/distributed or hosted elsewhere without the express permission from the copyright holders.

Camilleri, S.J., and C.J. Green, 2009, The impact of the suspension of opening and closing call auctions: Evidence from the National Stock Exchange of India, International Journal of Banking, Accounting and Finance, 1(3), 257-284.

liquid stocks did not benefit from the auction system, and that the closing auction may have been more effective than the opening. This could be because of a liquidity threshold which stocks have to pass to reap the information benefits of an auction (Schwartz, 2000, Ellul, Shin and Tonks, 2004). Indeed, following Comerton-Forde and Rydge (2006), auction price manipulation is less costly in case of less active securities. Given that suspension was related to software problems, it could also be that the structure of the auction contributed to the problems apparently experienced by less liquid stocks.

One limitation of the analysis is that we have concentrated on the effectiveness of call auctions from the point of view of the market as a whole. It is possible that auctions and other protocols may be of benefit to some market participants but not to others. Disaggregating the costs and benefits of auctions is an interesting subject for future research.

Overall though, our results have some important general implications. First, we find further support for the argument that call auctions are not necessarily a superior method for opening and closing an otherwise continuous market. The benefits or costs of call auctions appear to depend on the composition of the shares being traded. This suggests that future research will need to delve more deeply into the nature of the trading process in different shares in the market. Second, our results also show that it cannot be taken for granted that an opening or closing auction will improve share trading in a less liquid emerging market. On the NSE, it appears to have been precisely the less liquid securities which gained least from the call auction system. 
This article is (C) Inderscience Publishers and is being made available on www.um.edu.mt on condition that it cannot be further copied/distributed or hosted elsewhere without the express permission from the copyright holders.

Camilleri, S.J., and C.J. Green, 2009, The impact of the suspension of opening and closing call auctions: Evidence from the National Stock Exchange of India, International Journal of Banking, Accounting and Finance, 1(3), 257-284.

\section{References}

Admati, A. and Pfleiderer, P., 1988. A Theory of Intraday Patterns: Volume and Price Variability, Review of Financial Studies, 1(1), 3-40, Spring.

Aitken, M., C. Comerton-Forde and A. Frino, 2002. Closing Call Auctions And Market Liquidity, Unpublished Working Paper, University of New South Wales / Finance Discipline, University of Sydney.

Amihud, Y. and Mendelson, H., 1987. Trading Mechanisms and Stock Returns: An Empirical Investigation, Journal of Finance, 42(3), 533-553.

Amihud, Y. and Mendelson, H., 1991. Volatility, Efficiency and Trading: Evidence from the Japanese Stock Market, Journal of Finance, 46, 1765-1789.

Amihud, Y., Mendelson, H. and Lauterbach, B., 1997. Market Microstructure and Securities Values: Evidence from the Tel Aviv Stock Exchange, Journal of Financial Economics, 45, 365-390.

Amihud, Y., Mendelson, H. and Murgia, M., 1990. Stock Market Microstructure and Return Volatility: Evidence from Italy, Journal of Banking and Finance, 14, 423-440.

Angel, J.J. and Wu, S.Z. 2001. Calling the Open: Price Discovery Evidence from Nasdaq, Georgetown University Working Paper.

Ball, R. and Brown, P., 1968. "An Empirical Evaluation of Accounting Income Numbers”, Journal of Accounting Research, 159-178, Autumn.

Barry, C. and Brown, S., 1984. Differential Information and the Small Firm Effect, Journal of Financial Economics, 13(2), 283-294.

Biais, B., Hillion, P. and Spatt, C., 1999. Price Discovery and Learning during the Preopening Period in the Paris Bourse, Journal of Political Economy, 107 (6), 1218-1248.

Biais, B., and Pouget, S., 2000. Microstructure, Incentives, and the Discovery of Equilibrium in Experimental Financial Markets, Unpublished Working Paper, Toulouse University.

Breusch, T.S. and Pagan, A.R., 1980. The Lagrange Multiplier Test and its Application to Model Specifications in Econometrics, Review of Economic Studies, 47, 239-253.

Brown, S.J. and Warner, J.B., 1985. Using Daily Stock Returns: The Case of Event Studies, Journal of Financial Economics, 14, 3-31.

Cable, J. and Holland, K., 1999. Modelling Normal Returns In Event Studies: A Model-Selection Approach And Pilot Study, The European Journal Of Finance, 5, 331-341.

Caillaud, B. and Mezzetti, C., 2004. Equilibrium Reserve Prices in Sequential Ascending Auctions, Journal Of Economic Theory, 117, 78-95. 
This article is (C) Inderscience Publishers and is being made available on www.um.edu.mt on condition that it cannot be further copied/distributed or hosted elsewhere without the express permission from the copyright holders.

Camilleri, S.J., and C.J. Green, 2009, The impact of the suspension of opening and closing call auctions: Evidence from the National Stock Exchange of India, International Journal of Banking, Accounting and Finance, 1(3), 257-284.

Camilleri, S.J. and Green C.J., 2005. The Seasonality of Stock Price Volatility and Its Relevance to Excessive Price Movements: Empirical Evidence from the National Stock Exchange, India, Unpublished Working Paper, Loughborough University.

Chow, G.C., 1960. Tests of Equality Between Sets of Coefficients in Two Linear Regressions, Econometrica, 28(3), 591-605.

Comerton-Forde, C., 1999. Do Trading Rules Impact on Market Efficiency? A Comparison of Opening Procedures on the Australian and Jakarta Stock Exchanges, Pacific-Basin Finance Journal, 7, 495-521.

Comerton-Forde, C., and J. Rydge, 2006. Call Auction Algorithm Design and Market Manipulation, Journal of Multinational Financial Management, 16, 184-198.

Davies, R.J., 2003. The Toronto Stock Exchange Preopening Session, Journal of Financial Markets, 6(4), 491516.

Dia, M., and Pouget, S., 2004. Sunshine Trading in an Emerging Stock Market, Unpublished Working Paper, World Bank / Georgia State University.

Economides, N. and Schwartz, R.A., 1995. Electronic Call Market Trading, Journal of Portfolio Management, $21(3), 10-18$.

Ellul, A., Shin, H.S. and Tonks, I., 2004. How to Open and Close the Market: Lessons from the London Stock Exchange, LSE Financial Markets Group Working Paper No. dp 506, July.

Henke, H., and B. Lauterbach, 2005. Firm-Initiated And Exchange-Initiated Transfers To Continuous Trading: Evidence From The Warsaw Stock Exchange, Journal of Financial Markets, 8, 310-324.

Hillion, P. and Suominen, M., 2004. The Manipulation of Closing Prices, Journal of Financial Markets, 7, 351375 .

Jarque, C.M. and Bera, A.K., 1980. Efficient Tests for Normality, Homoscedasticity, and Serial Independence of Regression Residuals, Economics Letters, 6, 255-259.

Kairys, J.P. Jr., Kruza, R. and Kumpins, R., 2000a. Winners and losers from the introduction of continuous variable price trading: Evidence from the Riga Stock Exchange, Journal of Banking and Finance, 24, 603624.

Kairys, J.P. Jr., Kruza, R. and Kumpins, R., 2000b. A Tale of Three Cities: Is an Electronic Public Order Book Appropriate for Transition Economies? Unpublished Working Paper.

Kalay, A., Wei, L. and Wohl, A., 2002. Continuous Trading or Call Auctions: Revealed Preferences of Investors at the Tel Aviv Stock Exchange, Journal of Finance, 52 (1), 523-542. 
This article is (C) Inderscience Publishers and is being made available on www.um.edu.mt on condition that it cannot be further copied/distributed or hosted elsewhere without the express permission from the copyright holders.

Camilleri, S.J., and C.J. Green, 2009, The impact of the suspension of opening and closing call auctions: Evidence from the National Stock Exchange of India, International Journal of Banking, Accounting and Finance, 1(3), 257-284.

Kehr, C.H., Krahnen, J.P. and Theissen, E., 2001. The Anatomy of a Call Market, Journal of Financial Intermediation, 10, 249-270.

Kim, O. and Verrecchia, R., 1994. Market Liquidity And Volume Around Earnings Announcements, Journal of Accounting and Economics, Vol. 17, No. 2, 41-67.

MacKinlay, A.C., 1997. Event Studies in Economics and Finance, Journal of Economic Literature, 35, 13-39.

MacKinnon, J.G., 2002. Bootstrap Inference in Econometrics, Canadian Journal of Economics, 35(4), 615-645.

Madhavan, A., 1992. Trading Mechanisms in Securities Markets, Journal of Finance, 47(2), 607-641.

Madhavan, A. 2000. Market microstructure: A survey, Journal of Financial Markets, 3, 205-258.

Muscarella, C.J. and Piwowar, M.S., 2001. Market Microstructure and Securities Values: Evidence from the Paris Bourse, Journal of Financial Markets, 4, 209-229.

Pagano, M. and Schwartz, R., 2003. A Closing Call's Impact on Market Quality at Euronext Paris, Journal of Financial Economics, 68(3), 439-484.

Patell, J. and Wolfson, M., 1984. "The Intra-day Speed of Adjustment of Stock Prices to Earnings and Dividend Announcements", Journal of Financial Economics, June, Vol. 13, No. 2, pp. 223-252.

Ramsey, J.B., 1969. Tests for Specification Errors in Classical Linear Least-Squares Regression Analysis, Journal of the Royal Statistical Society B, 31(2), 350-371.

Ronen, T., 1998. Trading Structure And Overnight Information: A Natural Experiment From The Tel-Aviv Stock Exchange, Journal of Banking and Finance, 22, 489-512.

Roth, A.E., and A. Ockenfels, 2002. Last-Minute Bidding and the Rules for Ending Second-Price Auctions: Evidence From eBay and Amazon Auction on the Internet, The American Economic Review, 92(4), 10931103.

Schwartz, R.A., 2000. Building a Better Stock Market: New Solutions to Old Problems, Working Paper, AEIBrookings Joint Center For Regulatory Studies.

Shah, A. and Sivakumar, S., 2000. Changing Liquidity in the Indian Equity Market. Emerging Markets Quarterly, 62-71, Summer.

Shastri, K.A., Shastri, K. and Sirodom, K., 1995. Trading Mechanisms and Return Volatility: An Empirical Analysis of the Stock Exchange of Thailand, Pacific-Basin Finance Journal, 3, 357-370 


\section{Table 1: Data Periods Used for the Comparison Analysis and Event Study}

Call auctions were suspended on June $9^{\text {th }} 1999: \mathrm{t}=\mathrm{T}$. All other days are referred to in relation to June $9^{\text {th }}$. The comparison analyses include the tests of the differences in volatility, efficiency and liquidity. Open days are all days when trading took place on the exchange; closed days exclude weekends When working with prices, rather than returns, one further observation was available and so the preevent period used data from $\mathrm{T}-63$ until $\mathrm{T}-1$ and the post event period used data from $\mathrm{T}+1$ till $\mathrm{T}+63$.

\begin{tabular}{|c|c|c|c|c|c|c|c|c|}
\hline \multicolumn{9}{|c|}{ Panel A: Pre-Event and post-Event periods used for the comparison analyses } \\
\hline & \multicolumn{2}{|c|}{ First day } & \multicolumn{2}{|c|}{ Last day } & \multicolumn{4}{|c|}{ Number of days in period } \\
\hline & $\begin{array}{c}\text { Event } \\
\text { Time }\end{array}$ & $\begin{array}{l}\text { Date } \\
\text { (1999) }\end{array}$ & $\begin{array}{l}\text { Event } \\
\text { Time }\end{array}$ & $\begin{array}{c}\text { Date } \\
\text { (1999) }\end{array}$ & $\begin{array}{c}\text { Open } \\
\text { days }\end{array}$ & $\begin{array}{c}\text { Closed } \\
\text { days }\end{array}$ & $\begin{array}{l}\text { Week- } \\
\text { days }\end{array}$ & $\begin{array}{c}\text { Total } \\
\text { days }\end{array}$ \\
\hline $\begin{array}{l}\text { Pre-event } \\
\text { period }\end{array}$ & $\mathrm{T}-62$ & $\begin{array}{c}\text { 3rd } \\
\text { March }\end{array}$ & $\mathrm{T}-1$ & $\begin{array}{l}\text { 8th } \\
\text { June }\end{array}$ & 62 & 8 & 70 & 98 \\
\hline $\begin{array}{l}\text { Post-event } \\
\text { period }\end{array}$ & $\mathrm{T}+1$ & $\begin{array}{l}\text { 10th } \\
\text { June }\end{array}$ & $\mathrm{T}+62$ & $\begin{array}{c}\text { 3rd } \\
\text { Sept. }\end{array}$ & 62 & 0 & 62 & 86 \\
\hline \multicolumn{9}{|c|}{ Panel B: Estimation period and event window used for the event study } \\
\hline & \multicolumn{2}{|c|}{ First day } & \multicolumn{2}{|c|}{ Last day } & \multicolumn{4}{|c|}{ Number of days in period } \\
\hline & $\begin{array}{c}\text { Event } \\
\text { Time }\end{array}$ & $\begin{array}{l}\text { Date } \\
\text { (1999) }\end{array}$ & $\begin{array}{l}\text { Event } \\
\text { Time }\end{array}$ & $\begin{array}{c}\text { Date } \\
\text { (1999) }\end{array}$ & $\begin{array}{c}\text { Open } \\
\text { days }\end{array}$ & $\begin{array}{c}\text { Closed } \\
\text { days }\end{array}$ & $\begin{array}{l}\text { Week- } \\
\text { days }\end{array}$ & $\begin{array}{l}\text { Total } \\
\text { days }\end{array}$ \\
\hline $\begin{array}{l}\text { Estimation } \\
\text { period }\end{array}$ & $\mathrm{T}-62$ & $\begin{array}{c}\text { 3rd } \\
\text { March }\end{array}$ & $\mathrm{T}-3$ & $\begin{array}{l}\text { 4th } \\
\text { June }\end{array}$ & 60 & 8 & 68 & 94 \\
\hline $\begin{array}{l}\text { Event } \\
\text { window }\end{array}$ & $\mathrm{T}-2$ & $\begin{array}{l}\text { 7th } \\
\text { June }\end{array}$ & $\mathrm{T}+15$ & $\begin{array}{l}\text { 30th } \\
\text { June }\end{array}$ & 18 & 0 & 18 & 24 \\
\hline
\end{tabular}




\section{Table 2: Opening and Closing Distributions around Auction Suspension}

These tests compare the Mean Standard Deviations (MSD) for the opening and closing returns on the Nifty index during the period May $26^{\text {th }}$ to June $22^{\text {nd }} 1999$. Auctions were suspended effective June $9^{\text {th }}$ 1999 , so the data include ten trading days before suspension of the auctions, and a further ten days after suspension. The opening distributions were defined as the first thirty Nifty observations, sampled at 30-second intervals covering approximately the first 15 minutes of trading. The closing distributions were defined as the last thirty Nifty observations, sampled at 30-second intervals covering approximately the last 11 minutes of continuous trading, a 20-minute trading break, and the closing call auction. The 20 -minute break is treated as a 30 -second interval for computational purposes. The properties of these returns did not differ materially from those of the normal 30 -second returns.

Test 1 compares the MSDs before and after suspension.

Test 2 compares the standard deviation on June $8^{\text {th }}$ (the last auction date) with the MSD in the whole of the rest of the sample (19 days).

Test 3 compares the MSD before suspension, excluding June $8^{\text {th }}$ data, with the MSD after suspension, for the closing auction only.

\begin{tabular}{|l|l|c|c|}
\hline Test & & Opening: MSD & Closing: MSD \\
\hline 1 & Before suspension & 0.0010 & 0.0005 \\
\hline 1 & After suspension & 0.0015 & 0.0004 \\
\hline 1 & t statistic [95\% one-tail critical value] & $-1.4894[1.7341]$ & $1.7506[1.7341]$ \\
\hline 2 & 8th June & 0.0015 & 0.0009 \\
\hline 2 & Rest of sample & 0.0013 & 0.0004 \\
\hline 2 & t statistic [95\% one-tail critical value] & $-0.2759[1.7341]$ & $-1.7605[1.7341]$ \\
\hline 3 & Before suspension except 8th June & & 0.0005 \\
\hline 3 & After suspension & & 0.0004 \\
\hline 3 & t statistic [95\% one-tail critical value] & & $1.4241[1.7396]$ \\
\hline
\end{tabular}




\section{Table 3: Closing Call Auction Summary Statistics}

The table reports the closing call auction summary statistics for $8^{\text {th }}$ June 1999 as compared to the preceding five trading days. The rows show the following information: Trading Day, Auction Starting Time, Auction Ending Time, the Duration of the Auction, the \% change in the Nifty Index during the auction, the number of Nifty observations yielded by the auction software programme, and the average interval in between the Nifty observations during the call auction.

\begin{tabular}{|l|c|c|c|c|c|c|}
\hline Date (1999) & 8 June & 7 June & 4 June & 3 June & 2 June & 1 June \\
\hline Auction Starting Time & $15: 50: 15$ & $15: 50: 02$ & $15: 50: 02$ & $15: 50: 01$ & $15: 50: 01$ & $15: 50: 01$ \\
\hline Auction Ending Time & $15: 59: 33$ & $15: 52: 58$ & $15: 53: 33$ & $15: 53: 25$ & $15: 53: 15$ & $15: 54: 21$ \\
\hline $\begin{array}{l}\text { Duration Of Auction } \\
\text { (min-sec) }\end{array}$ & $9-18$ & $2-56$ & $3-31$ & $3-24$ & $3-14$ & $4-20$ \\
\hline$\%$ Nifty Change & $1.5 \%$ & $0.3 \%$ & $-0.1 \%$ & $0.0 \%$ & $-0.1 \%$ & $0.2 \%$ \\
\hline \# Observations & 41 & 37 & 37 & 38 & 39 & 37 \\
\hline Average Interval & 14 sec. & 5 sec. & 6 sec. & 5 sec. & 5 sec. & 7 sec. \\
\hline
\end{tabular}

\section{Figure 1: Closing Call Auctions - Nifty Log Returns}

Figure 1 shows the price movements registered during the closing call auctions as given in the intraday data files provided by NSE. The observations were not sampled at uniform time intervals

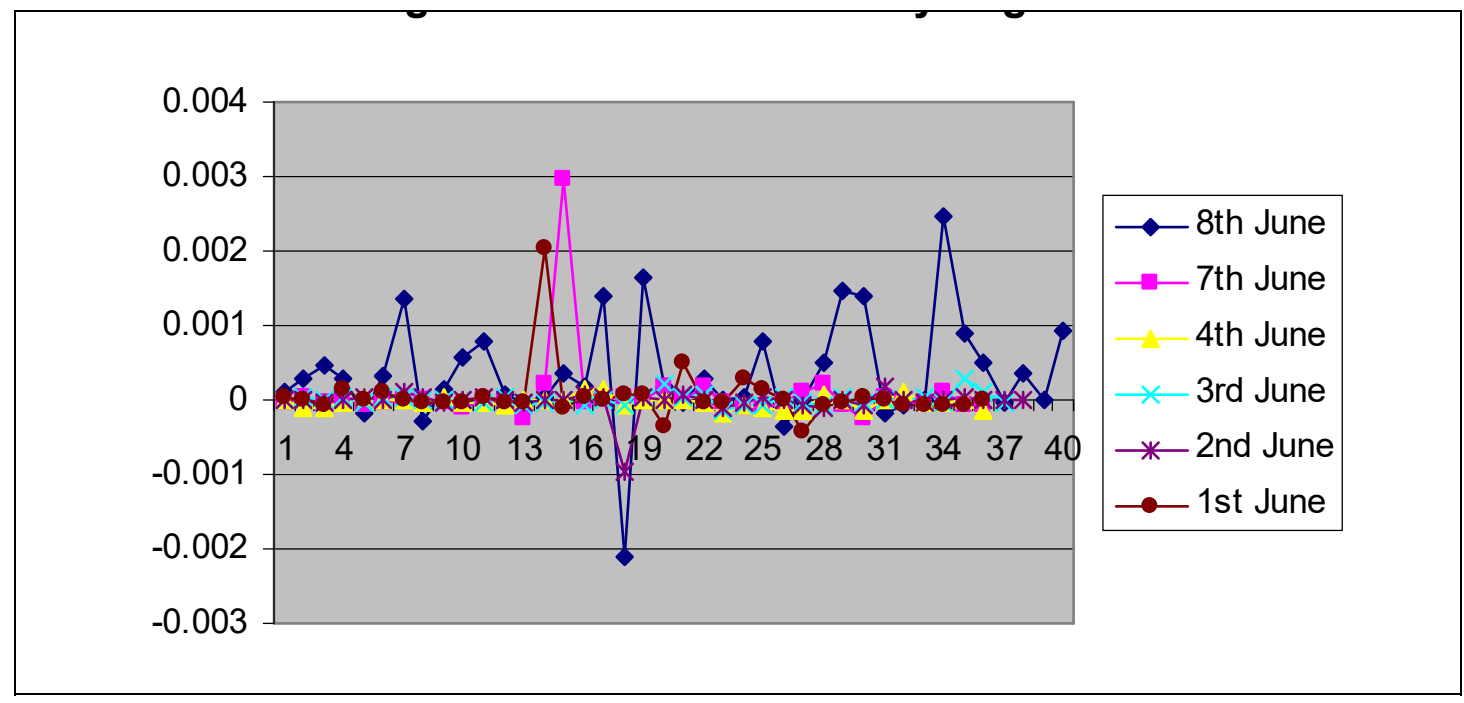




\section{Table 4: Summary Statistics for Call Auctions}

These three days were randomly selected from those that were not more than one and a half months distant from the event, and so as to avoid duplication of days of the week.

Sample A includes the 59 stocks with the lowest liquidity levels in terms of pre-event daily mean volume. Sample C includes the 59 stocks with the highest pre-event daily mean volume. The remaining 64 stocks were allocated to Sample B as "average liquidity" stocks.

Variable definitions are as follows.

Transactions $=$ Total Number of Transactions (all stocks)

Trades (\%) $=\%$ of shares which traded in the auction

ATS $($ IncZ) $=$ Average no of Transactions per share (incl. zero observations)

ATS (NoZ) =Average no of Transactions per share (excl. zero observations)

AUT (IncZ) $=$ Average no of Units Traded per share (incl. zero observations)

AUT $($ NoZ) $=$ Average no of Units Traded per share (excl. zero observations)

\begin{tabular}{|l|c|c|c|c|c|c|}
\hline & \multicolumn{2}{|c|}{$\begin{array}{c}\text { Monday } \\
\text { 3 May 1999 }\end{array}$} & \multicolumn{2}{c|}{$\begin{array}{c}\text { Thursday } \\
\text { 27 May 1999 }\end{array}$} & \multicolumn{2}{c|}{$\begin{array}{c}\text { Friday } \\
\text { 4 June 1999 }\end{array}$} \\
\hline & Open & Close & Open & Close & Open & Close \\
\hline Transactions & 1,274 & 2,995 & 1,446 & 13,361 & 3,392 & 5,642 \\
\hline Sample A & & & & & & \\
\hline Trades (\%) & $7 \%$ & $46 \%$ & $13.6 \%$ & $88 \%$ & $18.6 \%$ & $72.9 \%$ \\
\hline ATS (IncZ) & 0.4 & 1.6 & 0.5 & 7.8 & 0.6 & 10.1 \\
\hline ATS (NoZ) & 5.3 & 3.4 & 3.5 & 8.8 & 3.3 & 13.8 \\
\hline AUT (IncZ) & 49 & 217 & 34 & 1,307 & 141 & 830 \\
\hline AUT (NoZ) & 725 & 473 & 254 & 1,482 & 755 & 1,140 \\
\hline Sample B & & & & & & \\
\hline Trades (\%) & $45 \%$ & $80 \%$ & $41 \%$ & $95 \%$ & $39.7 \%$ & $81.3 \%$ \\
\hline ATS (IncZ) & 2.0 & 5.0 & 1.3 & 21.3 & 3.1 & 6.2 \\
\hline ATS (NoZ) & 4.5 & 6.3 & 3.2 & 22.7 & 8.0 & 7.6 \\
\hline AUT (IncZ) & 447 & 891 & 409 & 5,118 & 786 & 1,095 \\
\hline AUT (NoZ) & 986 & 1,118 & 1,005 & 5,459 & 2,012 & 1,348 \\
\hline Sample C & & & & & & \\
\hline Trades (\%) & $80 \%$ & $95 \%$ & $95 \%$ & $100 \%$ & $86.4 \%$ & $98.3 \%$ \\
\hline ATS (IncZ) & 13.6 & 28.5 & 14.7 & 120.1 & 42.0 & 59.9 \\
\hline ATS (NoZ) & 17.1 & 30.0 & 15.4 & 120.1 & 48.5 & 60.9 \\
\hline AUT (IncZ) & 4,290 & 8,201 & 4,117 & 43,515 & 15,243 & 19,912 \\
\hline AUT (NoZ) & 5,385 & 8,640 & 4,338 & 43,515 & 17,634 & 20,255 \\
\hline
\end{tabular}




\section{Table 5: Volatility Comparisons}

\section{Scaled Intra-Day Price Differences}

$\boldsymbol{D}_{i, t}$ is defined for each firm as $D_{i, t}=\left(P_{\text {high } i, t}-P_{\text {low } i, t}\right) / P_{\text {open } i, t}$, where: $P_{\text {high } i, t}, P_{\text {low } i, t}$ and $P_{\text {open } i, t}$ are the high, low and opening prices for security $i$ on day $t$ respectively.

$\boldsymbol{\sigma}\left(\boldsymbol{D}_{i, t}\right)$ are the standard deviations of each firm's $D_{i, t}$ in the pre- and post-event period.

\section{Overnight Return Reversals}

$\pi$ is the estimated coefficient in a regression of the daily return on the previous overnight return: $r_{i, t}=\mu_{i}+\pi_{i} r^{o}{ }_{i, t}+\varepsilon_{i, t}$, where $r_{i, t}$ and $r_{i, t}^{o}$ are the daily and overnight returns, respectively. These are: $r_{i, t}=\left(P_{\text {close } i, t}-P_{\text {open } i, t}\right) / P_{\text {open } i, t}, r_{i, t}^{o}=\left(P_{\text {open } i, t}-P_{\text {close } i, t-1}\right) / P_{\text {close } i, t-1}$, and $P_{\text {close } i, t-1}$ is the closing price for security $i$ on day $t-1$.

\section{Statistics}

The pre-event statistics were calculated using data from T-63 to T-1, and the post event statistics using data from $\mathrm{T}+1$ to $\mathrm{T}+63$. The mean and standard deviations are the cross-section statistics for all firms. The $t$ value is the $t$ statistic for the null hypothesis of no difference between pre-and post event data calculated using the paired means test which provides a firm-by-firm comparison; they are not a direct comparison of the means reported in the table. Critical values of $t$ for a two-tail test $(n=182)$ are 1.6533 (90\%); 1.9732 (95\%); 2.6033 (99\%)

\section{Conditional volatility}

Estimates of an asymmetric volatility EGARCH model of the daily returns $\left(r_{t}\right)$ on the NIFTY given by: $r_{t}=\varphi+\rho r_{t-1}+\varepsilon_{t} ; \varepsilon_{t} \sim N\left(0, h_{t}\right) ; \ln \left(h_{t}\right)=\omega+\alpha_{1} u_{t-1}+\gamma_{1}\left(\left|u_{t-1}\right|-E\left(\left|u_{t-1}\right|\right)\right)+\beta_{1} \ln \left(h_{t-1}\right)$; $u_{t} \sim N(0, \sigma)$. To ensure convergence, longer pre- and post-event periods were used than in other comparison tests: February $1^{\text {st }}-$ June $8^{\text {th }}$ and June $9^{\text {th }}-$ November $16^{\text {th }}$ respectively. We used the Nifty index to avoid non-trading in individual stocks.

\begin{tabular}{|c|c|c|c|c|c|c|c|c|}
\hline & \multicolumn{5}{|c|}{ Scaled Intra-Day Price Differences } & \multirow{2}{*}{\multicolumn{3}{|c|}{$\begin{array}{c}\begin{array}{c}\text { Overnight Return } \\
\text { Reversals }\end{array} \\
\pi \\
\end{array}$}} \\
\hline & \multicolumn{3}{|c|}{$D_{i, t}$} & \multicolumn{2}{|c|}{$\sigma\left(D_{i, t}\right)$} & & & \\
\hline & Pre-Event & \multicolumn{2}{|c|}{ Post-Event } & Pre-Event & Post-Event & \multicolumn{2}{|c|}{ Pre-Event } & Post-Event \\
\hline Mean & 0.0632 & \multicolumn{2}{|c|}{0.0564} & 0.0332 & 0.0332 & \multicolumn{2}{|c|}{-0.3439} & -0.3970 \\
\hline $\begin{array}{l}\text { Standard } \\
\text { Deviation }\end{array}$ & 0.0211 & \multicolumn{2}{|c|}{0.0226} & 0.0165 & 0.0491 & \multicolumn{2}{|c|}{0.1726} & 0.2288 \\
\hline t value & \multicolumn{3}{|c|}{$7.6443 * * *$} & \multicolumn{2}{|c|}{0.0027} & \multicolumn{3}{|c|}{$2.9097 * * *$} \\
\hline \multicolumn{9}{|c|}{ Conditional Volatility } \\
\hline & \multicolumn{4}{|c|}{ Pre-Event } & \multicolumn{4}{|c|}{ Post-Event } \\
\hline & \multicolumn{2}{|c|}{ coefficient } & \multicolumn{2}{|c|}{ t statistic } & \multicolumn{2}{|c|}{ coefficient } & \multicolumn{2}{|c|}{ t statistic } \\
\hline$\rho$ & \multicolumn{2}{|c|}{-0.04843} & \multicolumn{2}{|c|}{$(0.1121)$} & \multicolumn{2}{|c|}{0.0507} & \multicolumn{2}{|c|}{$(0.0921)$} \\
\hline$\alpha$ & \multicolumn{2}{|c|}{0.1013} & \multicolumn{2}{|c|}{$(0.2436)$} & \multicolumn{2}{|c|}{-0.0434} & \multicolumn{2}{|c|}{$(0.0964)$} \\
\hline$\gamma$ & \multicolumn{2}{|c|}{0.2791} & \multicolumn{2}{|c|}{$(0.2804)$} & \multicolumn{2}{|c|}{0.0646} & \multicolumn{2}{|c|}{$(0.1092)$} \\
\hline $\boldsymbol{\beta}$ & \multicolumn{2}{|c|}{0.1758} & \multicolumn{2}{|c|}{$(0.4948)$} & \multicolumn{2}{|c|}{$-0.9016 * * *$} & \multicolumn{2}{|c|}{$(0.1463)$} \\
\hline $\bar{R}^{2}$ & \multicolumn{4}{|c|}{0.0118} & \multicolumn{4}{|c|}{0.0018} \\
\hline
\end{tabular}

$* * *$ significant at $99 \%$ level; ** significant at $95 \%$ level; * significant at $90 \%$ level. 


\section{Table 6: Efficiency Comparisons}

\section{Relative Return Dispersion}

$R R D_{t}=\frac{1}{n} \sum_{i=1}^{n} \varepsilon^{2}{ }_{i t}$; where $\varepsilon_{i t}$ are the residuals from the market model for security $i$ at time $t$, and $n$ is the number of sampled securities.

\section{Relative Return Dispersion}

$\rho$ is the first-order autocorrelation coefficient calculated for each firm $\rho 2$ is the square of $\rho$.

\section{Statistics}

The pre-event statistics were calculated using data from $\mathrm{T}-63$ to $\mathrm{T}-1$, and the post event statistics using data from $\mathrm{T}+1$ to $\mathrm{T}+63$. The mean and standard deviations are the cross-section statistics for all firms. The $t$ value is the $t$ statistic for the null hypothesis of no difference between pre-and post event data calculated using the paired means test which provides a firm-by-firm comparison; they are not a direct comparison of the means reported in the table. Critical values of $t$ for a two-tail test $(n=182)$ are $1.6533(90 \%) ; 1.9732$ (95\%); $2.6033(99 \%)$

\section{Serial Correlation at the opening}

$\varphi$ is the first-order autocorrelation coefficient for returns on the NIFTY sampled at one minute intervals in the first hour of the day for each of 25 days before and after suspension of the auctions: respectively, 4th May 1999 - 8th June 1999 and 9th June 1999 - 14th July 1999. May $21^{\text {st }}$ and June 28th were excluded because of trading suspensions during the first hour of the day. We used the NIFTY index to avoid non-trading in individual stocks.

\section{Statistics}

Time mean and standard deviation are the time mean and standard deviation of these $\rho$. The t value is the $t$ statistic for the null hypothesis of no difference between pre-and post event mean values of $\rho$, calculated using the pooled variance.

\begin{tabular}{|c|c|c|c|c|}
\hline \multicolumn{5}{|c|}{ Relative Return Dispersion $\left(R R D_{t}\right)$} \\
\hline & \multicolumn{2}{|c|}{ Pre-Event } & \multicolumn{2}{|c|}{ Post-Event } \\
\hline Mean & \multicolumn{2}{|c|}{0.1272} & \multicolumn{2}{|c|}{0.1017} \\
\hline Standard Deviation & \multicolumn{2}{|c|}{0.1196} & \multicolumn{2}{|c|}{0.1127} \\
\hline t value & \multicolumn{4}{|c|}{$2.9308 * * *$} \\
\hline \multicolumn{5}{|c|}{ Serial Correlation of Returns } \\
\hline & \multicolumn{2}{|c|}{$\rho$} & \multicolumn{2}{|c|}{$\rho^{2}$} \\
\hline & Pre-Event & Post-Event & Pre-Event & Post-Event \\
\hline Mean & -0.0169 & 0.0791 & 0.0304 & 0.0292 \\
\hline Standard Deviation & 0.1739 & 0.1519 & 0.0409 & 0.0352 \\
\hline t value & \multicolumn{2}{|c|}{$6.3912 * * *$} & \multicolumn{2}{|c|}{0.2748} \\
\hline \multicolumn{5}{|c|}{ Serial Correlation at the opening $(\varphi)$} \\
\hline & \multicolumn{2}{|c|}{ Pre-Event } & \multicolumn{2}{|c|}{ Post-Event } \\
\hline Time mean & \multicolumn{2}{|c|}{0.3690} & \multicolumn{2}{|c|}{0.2261} \\
\hline Standard Deviation & \multicolumn{2}{|c|}{0.1109} & \multicolumn{2}{|c|}{0.1910} \\
\hline $\begin{array}{l}\text { t value } \\
99 \% \text { critical value }\end{array}$ & \multicolumn{4}{|c|}{$\begin{array}{l}3.2352 * * * \\
(2.6822)\end{array}$} \\
\hline
\end{tabular}


This article is (C) Inderscience Publishers and is being made available on www.um.edu.mt on condition that it cannot be further copied/distributed or hosted elsewhere without the express permission from the copyright holders.

Camilleri, S.J., and C.J. Green, 2009, The impact of the suspension of opening and closing call auctions: Evidence from the National Stock Exchange of India, International Journal of Banking, Accounting and Finance, 1(3), 257-284.

$* * *$ significant at $99 \%$ level; ** significant at $95 \%$ level; * significant at $90 \%$ level. 


\section{Table 7: Liquidity Comparisons}

Number of shares traded is calculated for each firm in the pre-event and post-event periods.

Volume/return ratio is the ratio of the number of shares traded in each firm to the daily absolute return. The daily returns include zeroes whereas the volumes do not. Therefore, we first computed daily return/volume ratios for each firm, then calculated the firm means, and finally the reciprocals of the means. This gave (mean) volume/return ratios for each firm in the pre- and post-event periods. The cross-section means and standard deviations of these ratios are reported in table 5; and the crosssection t-tests were performed on the volume/return ratios.

\section{Statistics}

The pre-event statistics were calculated using data from T-63 to T-1, and the post event statistics using data from $\mathrm{T}+1$ to $\mathrm{T}+63$. The mean and standard deviations are the cross-section statistics for all firms. The $t$ value is the $t$ statistic for the null hypothesis of no difference between pre-and post event data calculated using the paired means test which provides a firm-by-firm comparison; they are not a direct comparison of the means reported in the table. Critical values of $t$ for a two-tail test $(n=182)$ are $1.6533(90 \%) ; 1.9732$ (95\%); $2.6033(99 \%)$

\section{Volume time trend regresions}

Regression of $\operatorname{Ln}$ (Volume) on a constant, time trend and 2 dummies. $\mathrm{D}=0$ through June $8^{\text {th }} 1999$, and 1 thereafter. $\mathrm{D} \times$ trend is the product of the $\mathrm{D}$ and the time trend. The volume data are the daily total NSE share volumes from January 1995 through December 2003. $R^{2}=0.9034$.

\begin{tabular}{|c|c|c|c|c|}
\hline & \multicolumn{2}{|c|}{ Number of Shares Traded } & \multicolumn{2}{|c|}{ Volume/Return Ratio } \\
\hline & Pre-Event & Post-Event & Pre-Event & Post-Event \\
\hline Mean & 322,391 & 367,123 & 108,730 & 141,148 \\
\hline Standard Deviation & 986,908 & 942,824 & 284,978 & 338,722 \\
\hline t value & \multicolumn{2}{|c|}{$-1.9422 *$} & \multicolumn{2}{|c|}{$-4.4228 * * *$} \\
\hline \multicolumn{5}{|c|}{ Volume: time trend regression } \\
\hline & constant & trend & $\mathbf{D}$ & Dxtrend \\
\hline Coefficient & 9.4426 & 0.0033 & 2.0490 & -0.0021 \\
\hline t value & 348.8 & 78.5 & 27.9 & 36.6 \\
\hline
\end{tabular}




\section{Table 8: Market Model Estimates}

\section{Summary statistics}

Each column gives respectively the cross-section mean, median, standard deviation, minimum and maximum of the firm-specific estimates of the parameters of the market model.

\section{Diagnostics}

Each column gives respectively, the cross-section mean, minimum and maximum of the corresponding diagnostics from the firm-specific estimates of the market model. " $95 \% \mathrm{CV}$ " is the $95 \%$ critical value of each test; "No. of rejects" shows the number of shares where the null hypothesis was rejected at the $95 \%$ level indicating a possible misspecification; "\% rejects" shows the percentage of shares for which the null hypothesis was rejected at the $95 \%$ level

F-statistic: $\mathrm{F}$ test for zero slopes for the regression as a whole.

Autocorrelation: LM test for first-order autocorrelation (Breusch and Pagan, 1980).

Reset: Ramsey's test for functional form using squares of the fitted values (Ramsey, 1969).

Normality: Jarque and Bera's (1980) test for normality.

Heteroscedasticity:LM test for heteroscedasticity (Breusch and Pagan, 1980).

Predictive Failure: Chow's second test for structural breaks (Chow, 1960). This was applied to the 18 observations within the event window.

Chow: Standard Chow test for structural break at the mid-point of the estimation window.

\begin{tabular}{|c|c|c|c|c|c|c|}
\hline \multicolumn{7}{|c|}{ Summary Statistics } \\
\hline & Mean & Median & $\begin{array}{l}\text { Standard } \\
\text { Deviation }\end{array}$ & \multicolumn{2}{|c|}{ Min. } & Max. \\
\hline Intercept: $\alpha_{i}$ & 0.0008 & 0.0009 & 0.0041 & \multicolumn{2}{|c|}{-0.0118} & 0.0168 \\
\hline t-value: $t_{\alpha}$ & 0.1803 & 0.1958 & 0.8917 & \multicolumn{2}{|c|}{-2.4429} & 3.3704 \\
\hline Beta: $\beta_{i}$ & 1.203 & 1.2231 & 0.4433 & \multicolumn{2}{|c|}{0.1952} & 2.6905 \\
\hline t-value: $t_{\beta}$ & 4.6648 & 4.7075 & 1.7018 & \multicolumn{2}{|c|}{0.8237} & 9.0861 \\
\hline $\mathbf{R}^{2}$ & 0.2724 & 0.2764 & 0.1324 & \multicolumn{2}{|c|}{0.0116} & 0.5874 \\
\hline \multicolumn{7}{|c|}{ Diagnostics } \\
\hline & Mean & Min. & Max. & $95 \% \mathrm{CV}$ & $\begin{array}{l}\text { No. of } \\
\text { rejects }\end{array}$ & $\begin{array}{c}\% \\
\text { rejects }\end{array}$ \\
\hline F-statistic F $(1,58)$ & 24.6409 & 0.6785 & 82.5571 & 4.0000 & 169 & $93 \%$ \\
\hline Autocorrelation: $\chi^{2}(1)$ & 2.2013 & 0.0004 & 23.3566 & 3.8410 & 36 & $20 \%$ \\
\hline Reset: F $(1,57)$ & 1.4317 & 0.0000 & 21.2354 & 4.0000 & 21 & $12 \%$ \\
\hline Normality: $\chi^{2}(2)$ & 76.9884 & 0.0118 & 6645.50 & 5.9910 & 93 & $51 \%$ \\
\hline Heteroscedasticity: $\chi^{2}(1)$ & 1.2330 & 0.0004 & 36.3735 & 3.8410 & 13 & $7 \%$ \\
\hline Predictive Failure: F $(\mathbf{1 8 , 5 8}$ & \begin{tabular}{l|l|} 
8) & 1.0631 \\
\end{tabular} & 0.1022 & 10.6618 & 1.8100 & 23 & $13 \%$ \\
\hline Chow: $F(2,74)$ & 0.9962 & 0.0040 & 6.7545 & 3.1200 & 13 & $7 \%$ \\
\hline
\end{tabular}


Figure 2: Mean Differences for S.S.M.E. Random Sub-Samples in the Bootstrap Procedure.

The histogram shows a summary of the mean differences obtained when the S.S.R.E.s were randomly re-sampled 5000 times from the estimation period and the event window combined. Each bin covers all values within 0.005 of its centre.

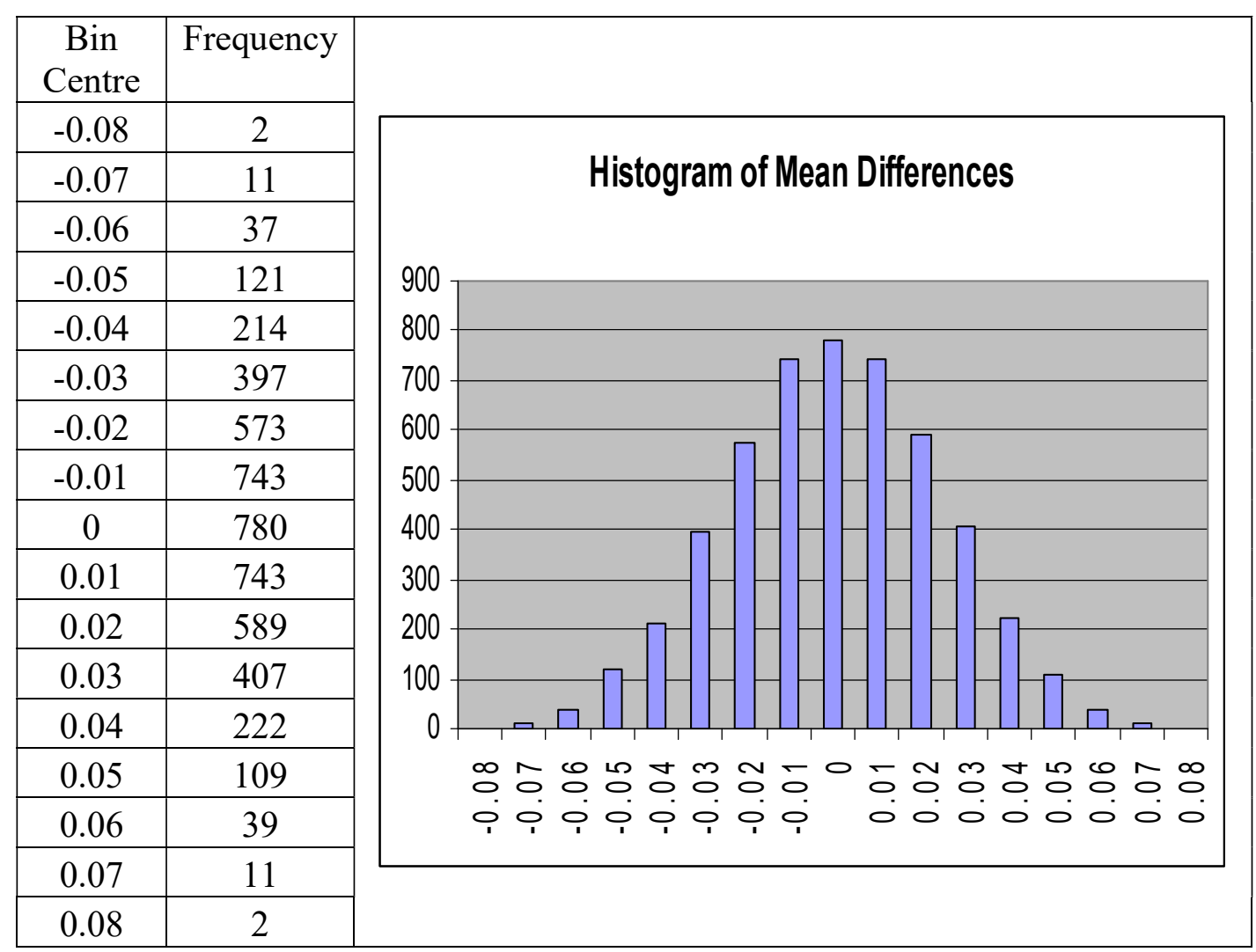

Figure 3: Average CARs during the Event Window 
This article is (C) Inderscience Publishers and is being made available on www.um.edu.mt on condition that it cannot be further copied/distributed or hosted elsewhere without the express permission from the copyright holders.

Camilleri, S.J., and C.J. Green, 2009, The impact of the suspension of opening and closing call auctions: Evidence from the National Stock Exchange of India, International Journal of Banking, Accounting and Finance, 1(3), 257-284.

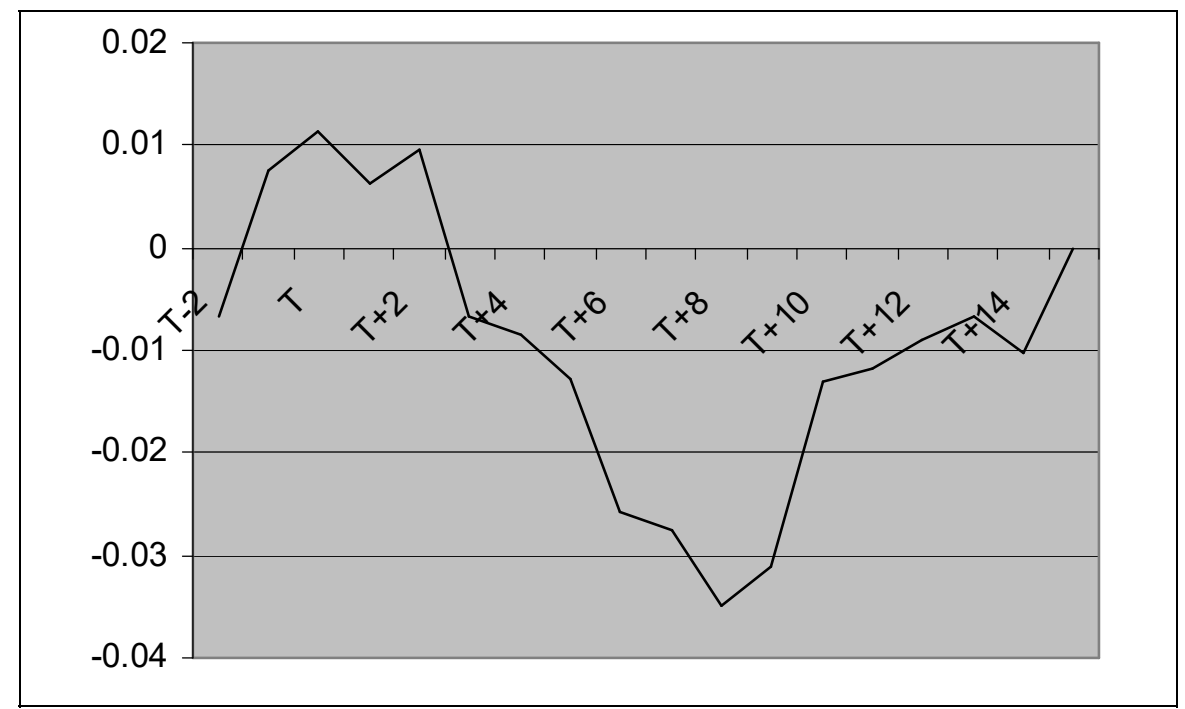




\section{Table 9: Stock liquidity and Changes in Volatility, Efficiency and Liquidity}

$\Delta$ SIDPD is the $\%$ change in the Scaled Intra-Day Price Difference between the pre-event and postevent period (table 2).

ORR is the coefficient $(\pi)$ in the regressions of the daily return on the previous overnight return.

$\Delta$ RRD is the $\%$ change in the relative return dispersion between the pre-event and post-event period.

$\Delta$ VRR is the \% change in the Volume-Return ratio between the pre-event and post-event period.

LD1 $=1$ for less liquid stocks: pre-event mean daily volume $\leq 40,000$ shares; zero otherwise;

LD2 = 1 for very liquid stocks: pre-event mean daily volume $\geq 140,000$ shares; zero otherwise.

These thresholds were set to divide the whole sample into three, approximately equal categories.

$\mathbf{t}$ statistics are shown in parentheses. Critical values of $\mathrm{t}$ for a two-tail test $(\mathrm{n}=182)$ are 1.6533

(90\%); $1.9732(95 \%) ; 2.6033(99 \%)$

\begin{tabular}{|l||c|c|c|c||}
\hline \multirow{2}{*}{$\begin{array}{l}\text { Dependent } \\
\text { Variable }\end{array}$} & \multicolumn{4}{c|}{ Liquidity Regressions } \\
\cline { 2 - 5 } & $\boldsymbol{C}$ & LD1 & LD2 & $\boldsymbol{R}^{\mathbf{2}}$ \\
\hline $\boldsymbol{\Delta}$ SIDPD & -0.1163 & 0.0421 & -0.022 & 0.026 \\
$(\boldsymbol{t}$ stat $)$ & $(5.73)^{* * *}$ & $(1.44)$ & $(0.75)$ & \\
\hline ORR & -0.0427 & 0.0132 & -0.0452 & 0.0102 \\
$(\boldsymbol{t}$ stat $)$ & $(1.39)$ & $(0.30)$ & $(1.02)$ & \\
\hline $\boldsymbol{\Delta}$ RRD & -0.1136 & 0.1559 & -0.1067 & 0.0138 \\
$(\boldsymbol{t}$ stat $)$ & $(1.00)$ & $(0.95)$ & $(0.65)$ & \\
\hline $\boldsymbol{\Delta}$ VRR & 0.4854 & 0.2496 & -0.295 & 0.0415 \\
$(\boldsymbol{t}$ stat $)$ & $(3.65)^{* * *}$ & $(1.30)$ & $(1.54)$ & \\
\hline \hline
\end{tabular}

$* * *$ significant at $99 \%$ level; $* *$ significant at $95 \%$ level; * significant at $90 \%$ level. 


\section{Table 10: Determinants of CARs}

\section{Panel A}

Regressors are: $\triangle \mathrm{SIDPD}=\%$ change in Scaled Intra-Day Price Difference; $\triangle \mathrm{RRD}=\%$ change in Relative Return Dispersion; $\Delta \mathrm{VRR}=\%$ change in Volume-Return Ratio; $L D 1, L D 2$ are the Liquidity dummy variables as in table 7

\section{Panel B}

Regressors are: ORR is the coefficient $(\pi)$ in the regressions of the daily return on the previous overnight return; $L D 1, L D 2$ are the Liquidity dummy variables as in table 7

$\mathbf{t}$ statistics are shown in parentheses. Critical values of $\mathrm{t}$ for a two-tail test $(\mathrm{n}=182)$ are 1.6533 (90\%); $1.9732(95 \%) ; 2.6033(99 \%)$

\begin{tabular}{|c|c|c|c|c|c|c|}
\hline \multicolumn{6}{|c|}{ Panel A. Dependent variable: Mean CARs T+9 through T+15 } \\
\hline $\boldsymbol{C}$ & ASIDPD & ARRD & AVRR & LD1 & LD2 & $\boldsymbol{R}^{\mathbf{2}}$ \\
\hline 0.048 & 0.225 & -0.001 & 0.024 & & & 0.174 \\
\hline$(4.00)^{* * *}$ & $(3.81)^{* * *}$ & $(0.10)$ & $(3.00)^{* * *}$ & & & \\
\hline 0.046 & 0.216 & -0.002 & 0.021 & 0.025 & -0.018 & 0.194 \\
\hline$(2.88)^{* * *}$ & $(3.66)^{* * *}$ & $(0.20)$ & $(2.63)^{* * *}$ & $(1.25)$ & $(0.90)$ & \\
\hline Panel B. Dependent variable: Mean CARs T+0 through T+8 \\
\hline $\boldsymbol{C}$ & ORR & & & LD1 & LD2 & $\boldsymbol{R}^{2}$ \\
\hline-0.039 & 0.070 & & & & & 0.018 \\
\hline$(3.90)^{* * *}$ & $(1.84)^{*}$ & & & & & \\
\hline-0.068 & 0.063 & & & 0.074 & 0.015 & 0.081 \\
\hline$(4.53)^{* * *}$ & $(1.70)^{*}$ & & & $(3.36)^{* * *}$ & $(0.68)$ & \\
\hline
\end{tabular}

$* * *$ significant at $99 \%$ level; $* *$ significant at $95 \%$ level; $*$ significant at $90 \%$ level.

\section{Figure 4: Different CAR patterns for stocks with differing liquidity levels}

Sample A includes 59 sampled stocks with the lowest liquidity levels in terms of pre-event daily mean volume. Sample C includes the 59 stocks with the highest pre-event daily mean volume. The remaining 64 stocks were allocated to Sample B as "average liquidity" stocks. 
This article is (C) Inderscience Publishers and is being made available on www.um.edu.mt on condition that it cannot be further copied/distributed or hosted elsewhere without the express permission from the copyright holders.

Camilleri, S.J., and C.J. Green, 2009, The impact of the suspension of opening and closing call auctions: Evidence from the National Stock Exchange of India, International Journal of Banking, Accounting and Finance, 1(3), 257-284.

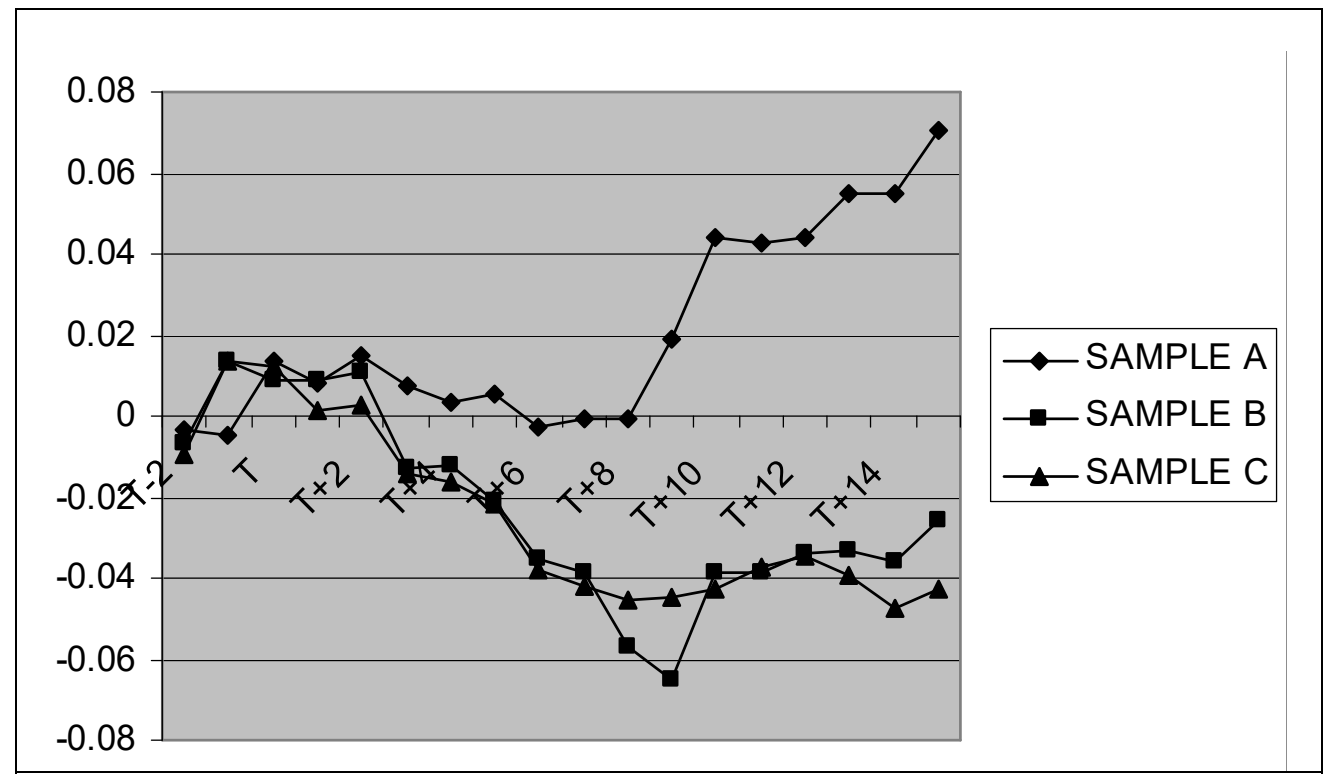


This article is (C) Inderscience Publishers and is being made available on www.um.edu.mt on condition that it cannot be further copied/distributed or hosted elsewhere without the express permission from the copyright holders.

Camilleri, S.J., and C.J. Green, 2009, The impact of the suspension of opening and closing call auctions: Evidence from the National Stock Exchange of India, International Journal of Banking, Accounting and Finance, 1(3), 257-284.

\section{Appendix 1}

\section{Table A1: Monthly Seasonality of Volatility}

Table A1 shows results for Monthly Seasonality of Volatility Regressions using Nifty Index daily observations from January $1^{\text {st }} 1999$ through December $31^{\text {st }} 2003$. Volatility is measured by the Modulus of Log Returns in regression 1; and by the Intra-Day Scaled Difference in regression 2. The first explanatory variable is a dummy taking a value of 1 during March \& April and zero otherwise, and the second explanatory variable is a dummy taking a value of 1 during August and zero otherwise.

These results are taken from: Camilleri, S.J. and Green C.J., 2005. The Seasonality of Stock Price Volatility and Its Relevance to Excessive Price Movements: Empirical Evidence from the National Stock Exchange, India, Unpublished Working Paper, Loughborough University.

\begin{tabular}{|c|c|c|c|c|c|c|}
\hline \multirow{3}{*}{ Volatility Proxy } & \multicolumn{3}{|c|}{ Regression 1} & \multicolumn{3}{|c|}{ Regression 2} \\
\hline & \multicolumn{3}{|c|}{ Modulus of Log Returns } & \multicolumn{3}{|c|}{ Intra-Day Scaled Difference } \\
\hline & Coefficient & \multicolumn{2}{|c|}{ S.E. } & Coefficient & \multicolumn{2}{|r|}{ S.E. } \\
\hline Intercept & 0.0113 & & $0.0003 * * *$ & 0.0207 & \multicolumn{2}{|c|}{$0.0004 * * *$} \\
\hline \multicolumn{7}{|l|}{ Dummy Variables: } \\
\hline March-April & 0.0043 & \multicolumn{2}{|c|}{$0.0008^{* * *}$} & 0.0080 & \multicolumn{2}{|c|}{$0.0010 * * *$} \\
\hline August & -0.0026 & & $0.0011 * * *$ & -0.0039 & & $0.0013 * * *$ \\
\hline \multirow{2}{*}{ Summary Statistics } & $\mathbf{R}^{2}$ & R-bar ${ }^{2}$ & F-Stat. & $\mathbf{R}^{2}$ & R-bar ${ }^{2}$ & F-Stat. \\
\hline & 0.0279 & 0.0264 & 18.011 & 0.0667 & 0.0652 & 44.800 \\
\hline
\end{tabular}

Notes: $\quad * * *$ Significant at the $99 \%$ level.

Table A2: Seasonally Adjusted Volatility Comparisons

These are the same comparisons as in text table 5 but based on adjusted SIDP and ORR data.

The SIDP was adjusted for the seasonal pattern shown in table A1. SIDP is 0.008 higher in March and April and 0.0039 lower in August. This implies that about two-thirds of our pre-event SIDP observations for each stock could be scaled down by 0.008 . As an approximation, the SIDP for each stock during the pre-event period was adjusted down by $0.0053(=0.008 \times 2 / 3)$. Similarly, about one-third of our post-event SIDP observations for each stock could be scaled up by 0.0039 . This was approximated by an upward adjustment of the SIDP for each stock by $0.0013(=0.0039 \times 1 / 3)$.

The $\boldsymbol{O R} \boldsymbol{R}$ was similarly adjusted for the seasonal pattern shown in table A1. The Return Modulus is 0.0043 higher in March and April, and therefore the ORR modulus for each stock in the pre-event period was adjusted down by $0.00287(=0.0043 \times 2 / 3)$. The Return Modulus is 0.0026 lower in August, and therefore the ORR modulus for each stock in the pre-event period was adjusted upwards by $0.00087(=0.0026 \times 1 / 3)$.

Critical values of $\mathrm{t}$ for a two-tail test $(\mathrm{n}=182)$ are $1.6533(90 \%) ; 1.9732(95 \%) ; 2.6033(99 \%)$

\begin{tabular}{|l|c|c|c|c|}
\hline \multirow{2}{*}{} & \multicolumn{2}{|c|}{ Scaled Intra-Day Price Differences } & \multicolumn{2}{c|}{ Overnight Return Reversals } \\
\cline { 2 - 5 } & Pre-Event & Post-Event & Pre-Event & Post-Event \\
\cline { 2 - 5 } & 0.0628 & 0.0565 & -0.3429 & -0.3973 \\
\hline Mean & 0.0210 & 0.0227 & 0.1721 & 0.2290 \\
\hline $\begin{array}{l}\text { Standard } \\
\text { Deviation }\end{array}$ & \multicolumn{2}{|c|}{$7.1823^{* * *}$} & \multicolumn{2}{c|}{$2.9836^{* * *}$} \\
\hline t value & \multicolumn{2}{c}{} \\
\hline
\end{tabular}

*** significant at $99 \%$ level. 
This article is (C) Inderscience Publishers and is being made available on www.um.edu.mt on condition that it cannot be further copied/distributed or hosted elsewhere without the express permission from the copyright holders.

Camilleri, S.J., and C.J. Green, 2009, The impact of the suspension of opening and closing call auctions: Evidence from the National Stock Exchange of India, International Journal of Banking, Accounting and Finance, 1(3), 257-284.

\section{Footnotes}

$1 \quad$ For instance Roth and Ockenfels (2002) presented evidence that subtle differences in internet auctions used for trading non-financial assets can cause pronounced differences in bidding behaviour.

2 The NSE circular announcing this change was issued on the same day.

3 Following suspension of the call auction on NSE, the time devoted to continuous trading was unchanged.

4 Ellul, Shin and Tonks (2004) identify a clear-cut comparison between the opening and closing calls on the London Stock Exchange and the parallel off-exchange dealer market. However, results for London may not be applicable in an emerging market.

5 Similar results are reported by Dia and Pouget (2004a) for the West-African Bourse.

6 Our sample period is characterized by occasional minor changes in trading hours

7 We thank the NSE for providing us with trial copies of these data.

8 The rationale for using the BSE index for certain analyses is explained in section 5.1 below.

9 We thank Susan Thomas for helpful correspondence on the suspension. Perhaps not surprisingly, the NSE did not issue a public statement about the reasons for the suspension and, despite several efforts, we were unable to obtain from them any further background information. However, as we discuss next, our check of the pre-suspension data suggests that any software problems that did exist did not have a measurable effect on the pricing process except in the very last auction before suspension.

10 NSE regulations permit release of earnings news at any time in the trading day, and so there is no overnight effect arising from the systematic release of earnings news out of trading hours.

11 We used the Nifty index to avoid non-trading in individual stocks.

12 We began with the last 26 trading days of the auction regime (4th May 1999 - 8th June 1999) and the first 26 trading days of the post-auction regime (9th June 1999 - 14th July 1999). May 21st and June 28th 1999 were dropped from this sample because of trading suspensions during the first hour of the day, leaving 25 trading days in each regime. We used the Nifty index to avoid non-trading in individual stocks.

13 Five trading days were omitted from the sample because the BSE was closed on these days.

14 The bootstrap routine was obtained from http://www.resample.com/content/about.shtml (accessed 1st March 2004).

15 That is: the probability of obtaining the reported mean difference by coincidence is less than 1 in 5000 .

16 It is possible that the concentration of annual company reports in the pre-event window may bias the CARs. To check this we re-estimated the cross-sectional CARs omitting securities which went ex-dividend in the pre-event period or the event window. The pattern of CARs for the remaining 116 securities (available from the authors on request) was similar to that for the whole sample.

17 As a check on the cross-section average, the sample was randomly split into 5 sub-samples (three containing 36 stocks, two containing 37) and the average CARs recalculated for each sub-sample. The plots of the five sub-samples (available from the authors on request) were similar to the overall pattern of figure 3 .

18 These measures were selected on the basis of a higher significance level in the VEL comparisons. 